$$
\begin{array}{r}
\text { OS BANCO } \\
\text { CERAMICA MARAJ } \\
\text { SEUS CONTEXTOS E POSS } \\
\text { SIGNIFICADOS SIMBÓL }
\end{array}
$$




\section{OS BANCOS DE CERÂMICA MARAJOARA: SEUS CONTEXTOS E POSSÍVEIS SIGNIFICADOS SIMBÓLICOS}

\section{A I A NA TRAVASSOS A L VES}

UNIVERSIDADE FEDERAL DO PARÁ, BELÉM, BRASIL

D E N I S E P A H L S C H A A N

UNIVERSIDADE FEDERAL DO PARÁ, BELÉM, BRASIL 


\title{
OS BANCOS DE CERÂMICA MARAJOARA: SEUS CONTEXTOS E POSSÍVEIS SIGNIFICADOS SIMBÓLICOS
}

\section{Resumo}

Esse artigo apresenta um estudo sobre bancos da fase marajoara da tradição Policrômica da Amazônia, realizado a partir de dados obtidos durante escavações e análises de laboratório. Informações etnohistóricas e etnográficas são usadas para construir hipóteses sobre os possíveis usos e significados dos prováveis assentos circulares de cerâmica encontrados na ilha de Marajó, mas raros em outros contextos etnográficos e arqueológicos. A ausência de bancos nos contextos funerários é tida como indicação de seu uso mundano, ainda que possam ter sido usados em contextos rituais que não o funerário. O exame da iconografia desses objetos, onde predominam os motivos incisos que parecem imitar esteiras produzidas com fibras trançadas, sugere seu uso como assento. Finalmente, uma descrição etnográfica de uma cerimônia de castração feminina é apresentada, mostrando, o uso, nesse contexto, de quatro objetos exóticos e raros, mas que fazem parte da cultura material da fase marajoara. A analogia etnográfica, neste caso, traz novas possibilidades para entender os possíveis usos para os bancos de cerâmica marajoara.

Palavras-chave: bancos de cerâmica, fase marajoara, arqueologia amazônica.

\section{THE MARAJOARA POTTERY STOOLS: THEIR CONTEXTS AND POSSIBLE SYMBOLIC MEANINGS}

\begin{abstract}
This article presents a study on the pottery stools of the marajoara phase of the Amazonian polychrome tradition, based on data obtained during fieldwork and laboratory analysis. Ethnohistorical and ethnographic information are used to construct hypotheses about the possible uses and meanings of the probable circular pottery seats found on the island of Marajó, which rare in other ethnographic and archaeological contexts. The absence of stools in funerary contexts is taken as an indication of its mundane use, although they may have been used in other ritual contexts as well. The analyses of these objects' iconography, where incised designs predominate, suggest that they might mimic woven fiber mats;
\end{abstract}


therefore it is logic they would serve as seats. Finally, an ethnographic description of a female castration ceremony is presented showing the use of four exotic and rare objects, which are all part of the marajoara phase material culture assemblage. The ethnographic analogy in this case brings new possibilities to understand the possible uses for marajoara phase stools.

Keywords: pottery stools, marajoara phase, amazonian archaeology.

\section{LOS BANQUILLOS DE CERÁMICA MARAJOARA: SUS CONTEXTOS Y POSIBLES SIGNIFICADOS SIMBÓLICOS}

\section{Resúmen}

En este artículo se presenta un estudio sobre los bancos de la fase marajoara de la tradición polícroma de la Amazonía, a partir de los datos obtenidos durante las excavaciones y análisis de laboratorio. Informaciones etnohistórica y etnográfica son utilizadas para construir hipótesis sobre los posibles usos y significados de los asientos circulares de cerámica que se encuentran en la isla de Marajó, pero poco frecuente en otros contextos etnográficos y arqueológicos. La ausencia de bancos en contextos funerarios se toma como una indicación de su uso mundano, a pesar de que pueden haber sido utilizados en contextos rituales que no sea el de pompas fúnebres. El examen de la iconografía de estos objetos, donde la mayoría de los elementos de decoración parecen imitar esteras tejidas de fibra, sugiere su uso como asiento. Por último, una descripción etnográfica de una ceremonia de castración femenina se presenta mostrando el uso, en este contexto, de cuatro objetos exóticos y raros, pero presentes en la cultura material de la fase marajoara. La analogía etnográfica, en este caso, ofrece nuevas posibilidades para entender los posibles usos de los bancos de la fase marajoara. Palabras-clave: asientos de cerámica, fase marajoara, arqueología amazónica. 


\section{INTRODUÇÃO}

Os bancos de cerâmica da fase marajoara da tradição polícroma amazônica são espessos discos de cerâmica acoplados ao topo de bases anelares (Meggers e Evans 1957: 381). O assento é em geral plano ou ligeiramente côncavo; em alguns casos encontra-se uma perfuração central. Os assentos e suportes desses bancos são comumente decorados com técnicas e motivos similares aos encontrados nos demais objetos de cerâmica da fase marajoara, como vasos e pratos, com a exceção de um tipo de decoração incisa que imita trançados de fibras vegetais e são quase que exclusivos dos bancos. Muitos possuem acabamento rústico e não são decorados. O mais curioso é que, apesar de estarem presentes no registro arqueológico enquanto objetos inteiros ou fragmentos, esses objetos não se encontram representados na iconografia, como assentos para personagens antropomorfas, como se observa em outras culturas arqueológicas do baixo e médio Amazonas ${ }^{1}$. Uma possível exceção seria a urna do tipo $\mathrm{Pa}$ coval Inciso, onde a figura feminina está sentada sobre um tamborete cilíndrico, com as pernas dispostas para a frente (Figura 1). Mesmo neste caso, a representação do banco seria questionável, uma vez que o assento não é visível e se poderia dizer que se trata simplesmente do corpo inferior do vaso.

O fato de a absoluta maioria dos bancos da fase marajoara serem circulares também coloca uma dificuldade adicional. Os bancos conhecidos na iconografia arqueológica amazônica são em geral retangulares, assim como o são os bancos etnográficos (Ribeiro 1988). Há, contudo casos raros de bancos marajoaras retangulares (McEwan 2001: 178; fig. 7.3), que se assemelhariam mais aos etnográficos, apesar do tamanho reduzido. Talvez por isso alguns autores tenham duvidado que os "bancos" da fase marajoara tenham sido realmente utilizados como assentos. McEwan (2001: 178) referese a eles como "bancos ou apoios de cabeça", aventando outra possibilidade de uso. Palmatary (1950: 296) os chama tanto de bancos quanto de "suportes de panela" (pot stands), mas não chega a elaborar com relação a essa função. Uma maneira de avaliarmos a função desses objetos seria observar seu contexto arqueológico, tendo em vista a falta de referenciais iconográficos. Raramente, entretanto, os bancos tem sido mencionados em relatos de escavações. Roosevelt (1991) pouco explora os bancos, mas supõe que seriam objetos relacionados a rituais funerários, pelo fato de serem encontrados inteiros nos sítios arqueológicos. Realmente percebe-se que, além dos bancos serem encontrados fartamente na forma de fragmentos em sítios - só perdendo para as tangas em termos de sua originalidade e abundância (Meggers and Evans 1957:381) - muitos bancos são encontrados inteiros, o que sugere a "curadoria" desses objetos e possivelmente sua deposição votiva.

Afinal, para que serviriam os bancos da fase marajoara? Seriam simplesmente objetos para sentar, em situações diversas? Quais os significados de suas decorações? A que contextos são associados? De que maneira os bancos 


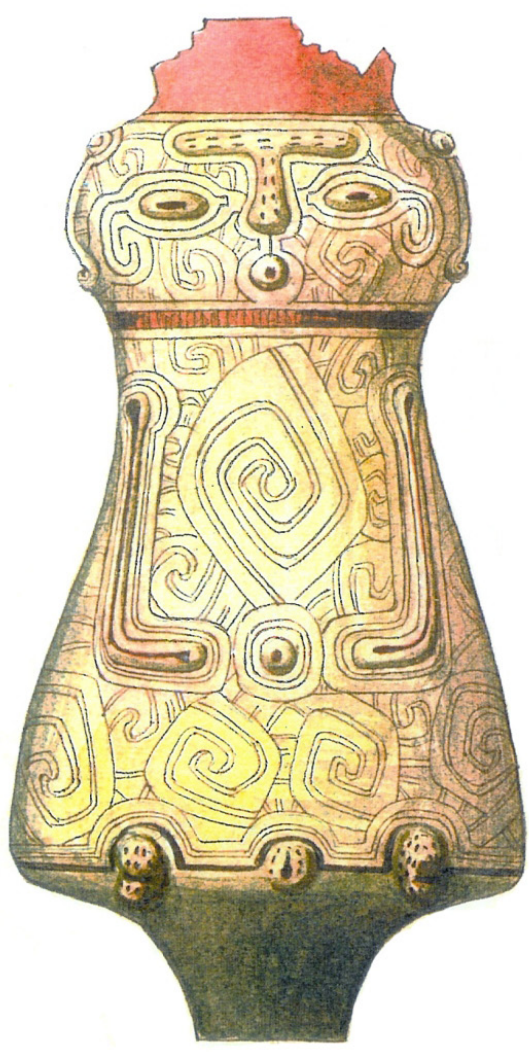

Figura 1 - Urna marajoara do Acervo do Museu Nacional (tipo pacoval inciso); aquarela de Manoel Pastana, 1937, acervo do Museu do Forte, Belém/PA.

se colocam em comparação aos demais objetos domésticos, rituais e festivos das sociedades marajoara? Em que os bancos da fase marajoara diferem de bancos em outras sociedades etnográficas e arqueológicas? Queremos nesse artigo refletir sobre essas questões e contribuir para o conhecimento sobre o uso dos bancos entre as sociedades amazônicas pré-colombianas.

\section{O HOMEM E A MULHER SENTADOS}

"La estatuaria pública es una forma de rendirle culto al hombre superior, al héroe. En el mundo occidental, u occidentalizado, la gran mayoría de estos personajes es representada de pie. Se reserva el sentarse para los pensadores, los héroes del espíritu; pero siempre se ha preferido a los guerreros en sus diversas modalidades. No obstante, la noción de imperio, de permanencia, fuerza sustentadora y ordenadora, la sigue dando el hombre firme en un trono" (Urbina 1994).

Urnas funerárias representando indivíduos sentados sobre pequenos bancos retangulares não são raras entre as culturas arqueológicas da bacia Amazônica. Aparecem em urnas funerárias no baixo Amazonas (McEwan 2001) e no rio Maracá, no Amapá (fase maracá) (Guapindaia 2001). Na cerâmica tapajônica, há vasos antropomorfos representando figuras masculinas sentadas sobre bancos de formato retangular (McEwan 2001: 176; fig. 7.1).

As urnas funerárias encontradas nas cavernas de Maracá, no Amapá, são antropozoomorfas, representando um jaboti/homem ou jaboti/mulher sentados eretos sobre bancos retangulares zoomorfos (Guapindaia 2001; Penna 1877). A postura é imponente. As mãos repousam sobre os joelhos, enquanto os cotovelos são projetados para frente. Nos sítios habitação da fase maracá, entretanto, parecem não ter sido encontrados bancos de cerâmica desacoplados de urnas funerárias. É possível que tenham existido bancos feitos de madeira, que não tenham sobrevivido ao tempo. 
Indivíduos sentados são encontrados também em registros rupestres no rio Caquetá, na Colômbia, entre Araracuara e Peñas Negras, segundo a interpretação feita por Urbina de figuras que tem sido interpretadas como antropomorfos ou zoormorfos (rãs). Urbina argumenta que o "pênis" ou "rabo curto" que se projeta para baixo entre as pernas abertas, descrito assim por alguns autores, seriam simplesmente bancos estilizados (Urbina 1994).

Tanto no caso das urnas do baixo Amazonas, onde bancos acompanham figuras masculinas realistas, como no caso da fase maracá, onde os bancos acompanham a estatuária de ambos os gêneros, representados por personagens híbridos (humano-animal) que sugere a representação do sobrenatural (Ribeiro 1987), reveste-se de importância o ato ou postura de sentar, o que tem sido interpretado enquanto atitude que indica hierarquia, poder e diferenciação social e que encontraria relação com rituais religiosos de vários tipos. McEwan (2001: 179) indica que o uso dos bancos é identificado arqueológica e etnograficamente em uma vasta região geográfica que engloba a floresta tropical, a baixa América Central e o Caribe. Segundo o autor, isso possibilita pensar na grande profundidade temporal e vasta distribuição geográfica, o que nos habilitaria ao uso da analogia como recurso interpretativo.

A literatura etnohistórica amazônica é lacônica com relação a bancos, o que não causa surpresa, se levamos em conta que pouco da cultural material foi relatada durante as primeiras viagens de reconhecimento do rio Amazonas. Acuña (1641), no entanto, quando se refere aos "Águas", indica claramente que, no século XVI, utilizavam-se bancos bastante semelhantes aos conhecidos etnograficamente:

"Es esta gente la de mas razón, y mejor gobierno que ay em todo el rio (...) Son tan sujetos y obedientes a sus principales caciques, que no han menester mas de una palabra para ver luego ejecutado lo que ordenan" (...) "Tienen em las barrancas donde moran muy buen barro para todo género de vasijas, y aprovechándose del, fabrican grandes ollerías; em que labran tinajas, ollas, hornos em que cuezen sus harinas [...] por el Amazonas abajo, a la Vanda del sur, corren los Caripunas, Y Zurinas[...] hacen bancos forjados en forma de animales [ênfase nossa], con tanto primor, y tan acomodados para tener el cuerpo con descanso".

Tanto os bancos de madeira tucano do século XX como os bancos cerâmicos da fase maracá, provavelmente datados dos séculos XV e XVI são zoomorfos, portanto, estão de acordo com a descrição do cronista.

$\mathrm{Na}$ América Central e no Caribe, mais do que na Amazônia, a menção a bancos é recorrente na literatura etnohistórica. Os Taíno, grupo Arawak que habitava o Caribe na época da chegada de Cristóvão Colombo, os chamavam duho, ou assentos rituais, que eram usados como símbolo de poder e status social. Usar o duho era prerrogativa daqueles que se colocavam acima dos comuns e podiam se conectar aos antepassados. O uso dos duhos era acompanhado pelo consumo 
de drogas alucinógenas e pelo exercício do poder. Tais objetos eram parte da cultura material dos cacicados que existiram de 1200 a 1500 nas grandes Antilhas (Ostapkowicz 1998: 42). Os duhos eram em sua maioria esculpidos em madeira (porém há exemplares em coral e rocha), com características zoomórficas e antropomórficas, às vezes feitos com encostos, e decorados com incisões e entalhes primorosos. Olhos, boca, orelhas, ombros eram ocasionalmente adornados com ouro, concha ou pedras preciosas. Mais de 100 duhos existem em museus e coleções particulares, provenientes de Hispaniola, Porto Rico, das Bahamas, das Ilhas Turcas e Caicos, e alguns poucos da Jamaica e Cuba. Para Ostapkowicz (1998), não restam dúvidas de que os duho eram objetos da elite, verdadeiros símbolos de poder.

$\mathrm{Na}$ etnografia mais recente de populações indígenas amazônicas encontramos muitas descrições sobre usos de bancos. Os processos de fabricação dos bancos e seu uso foram mais bem investigados para os tukano, um grupo indígena que habita o noroeste Amazônico, entre o Brasil e a Colômbia. A produção do banco tukano, chamado kumurõ, envolve, em seu início, a busca da madeira apropriada para sua construção. $\mathrm{O}$ banco pode ter vários usos, e é esculpido por homens a partir de uma única tora de madeira, e pintado com motivos da cestaria. $\mathrm{O}$ processo de produção é demorado e demanda uma série de procedimentos ritualizados, executados durante um período de 72 horas (Cabalzar 2003).

Como vários autores têm demonstrado, o banco possui grande importância simbólica para as sociedades indígenas; entre os desâna, estudados por Gerardo Reichel-Dolmatoff (1976), o banco aparece no mito de origem do mundo como um dos elementos invisíveis de que a bisavó do universo (criadora do mundo) se constitui. Costumam referirse a pessoas que tem estabilidade (personalidade calma e firme) como pessoa que sabe sentar, e, ao contrário, as que não sabem ter assento são pessoas impacientes (esquentadas) e por esse motivo acabam atraindo males para si e para a aldeia (gerando conflitos), sendo dessa forma permitido o uso do banco somente por aqueles considerados aptos. O banco é símbolo de sabedoria, estabilidade e reflexão; quando alguém está sentado está protegido por espíritos benevolentes; nesse sentido é um objeto poderoso para xamãs, chefes e guerreiros (McEwan 2001). Segundo Fernando Urbina (1994) sua presença, na casa comunal, com ou sob os corpos dos homens sabedores sentados, justifica-se pela crença, em alguns grupos, de que o homem comum está relacionado ao efêmero. O homem que se senta está firme na terra, mas os que de fato estão firmes são os deuses e os mortos; os deuses porque criaram o mundo, os mortos porque viveram nele.

Fernando Galhano fez um trabalho acerca de esculturas e objetos decorados da Guiné portuguesa, entre os quais o banco, ao qual dedica alguma atenção. De acordo com Galhano (1971), na Guiné o banco é usado por homens de idade e com certo respeito dentro do grupo nas atividades cerimoniais, e por 
esse motivo está ligado aos "Irãs" (espíritos). Seu uso é proibido às mulheres; o mesmo banco passa de velho para velho dentro de cada família; quando morrem todos os indivíduos da família, o banco fica no templo da comunidade. Aqui também se pode observar o caráter restritivo e diferenciador do uso do banco.

O banco aparece em algumas etnografias como acompanhamento funerário, e nem sempre fica claro se está simplesmente junto com os demais pertences do morto ou se possui papel especial. Entre os pakaa-nova, que praticam canibalismo funerário, os bancos são queimados com todos os pertences do falecido, com a intenção tanto de afastar a lembrança que poderiam trazer como de afastar seu espírito, que acreditam passar por um estágio transitório até partir para o mundo dos mortos, ou transmutar-se em animal (Villaça 1993).

Pineda (1994) fala também sobre a presença dos bancos em rituais fúnebres, onde pessoas importantes são enterradas assentadas no banco juntamente com pertences e com bebida, sendo que os homens comuns seriam enterrados sem bancos, sem pertences e com um ritual funerário mais simples.

O uso do banco em diversas sociedades também faz parte do ritual xamanístico de consumir tabaco, ayahuasca ou inalar rapé. Quando, na atividade ritual, o indivíduo senta e fuma, a fumaça forma um caminho que liga o mundo dos vivos ao dos ancestrais mortos (McEwan 2001; Pineda 1994). A decoração dos bancos, com formas de cabeças ou patas de animais em suas extremidades também estaria relacionada ao seu caráter xamâni- co; ao sentar-se, o pajé recebe ajuda do espírito do animal que o banco representa. Nessa perspectiva, os xamãs galibi, grupo caribe da costa Venezuelana, usam bancos que representam animais como jacaré, tartaruga, papagaio, jaguar e urubu, entre outros (Zerries 1970).

Os kaiowá, da reserva indígena em Dourados, utilizam bancos em rituais de iniciação ou cura, onde a pessoa objeto do ritual fica sentada, enquanto os demais dançam ou rezam à sua volta (Paschoalick 2001).

\section{CONTEXTOS ARQUEOLÓGICOS}

Desde o final do século XIX, os sítios arqueológicos da ilha de Marajó tem sido escavados, e centenas de objetos de cerâmica tem desde então entrado nas coleções de museus do mundo todo (Schaan 2009). Apesar disso, são raras e lacônicas as descrições de bancos em contextos arqueológicos. Meggers e Evans (1957: 381), em sua monografia sobre a foz do Amazonas, ressaltam as diferenças estilísticas entre bancos recolhidos em diferentes sítios, a partir de relatos de diversos exploradores, para os quais não são disponíveis informações contextuais. No sítio Pacoval do Arari (Figura 2), por exemplo, teriam sido encontrados bancos com decorações que envolvem incisões e engobo, principalmente (anajás inciso simples, anajás inciso branco, arari exciso simples, e arari exciso com engobo duplo²), mas acreditam que um exemplar joanes pintado (que é mais raro) presente na coleção do USNM (United States National Museum) teria vindo do Pacoval. 
Ainda segundo Meggers e Evans, as escavações de Farabee no sítio Fortaleza teriam produzido 15 bancos, a maioria decorada com incisões e sem engobo, mas alguns trariam representações estilizadas de faces humanas sobre o suporte (como o banco da Figura 15). Já em suas escavações no sítio Camutins, encontraram tanto em superfície quanto em profundidade bancos de decoração singela, com incisões e sem engobo.

Nimuendaju encontra fragmentos de bancos em suas escavações no teso Bacuri, na região nordeste da ilha de Marajó; entanto, não é fornecida informação contextual. Dois dos bancos possuem perfuração central. Todos possuem apêndices zoomorfos no assento. Um dos bancos é decorado com um aplique no formato de cobra sobre o suporte, onde está representada a ca- beça e o corpo decorado com losangos concêntricos (Nimuendaju 2004: 190, plate 017) (Figura 10-E).

Durante as prospecções realizadas nos 34 tesos do sitio Camutins pela segunda autora, apenas nos tesos 1 (Camutins) e 17 (Belém) - os maiores, que comporiam o núcleo de poder político - foram encontrados fragmentos de bancos. Isso indica o uso restrito desse tipo de objeto, tendo sido observado o mesmo para as tangas (Schaan 2004, 2009).

Dentre os nove bancos ou fragmentos de bancos coletados no teso 1 (Figura 3) há dois fragmentos de bancos sem decoração (Figura 3-G; 3-I), um deles com o centro perfurado (Figura 3-G). Os sete decorados incluem tipos incisos e excisos. O tamanho do assento varia entre 15,5 e 20,5cm (mediana de $18 \mathrm{~cm}$ ), o que os caracteriza como de tamanho

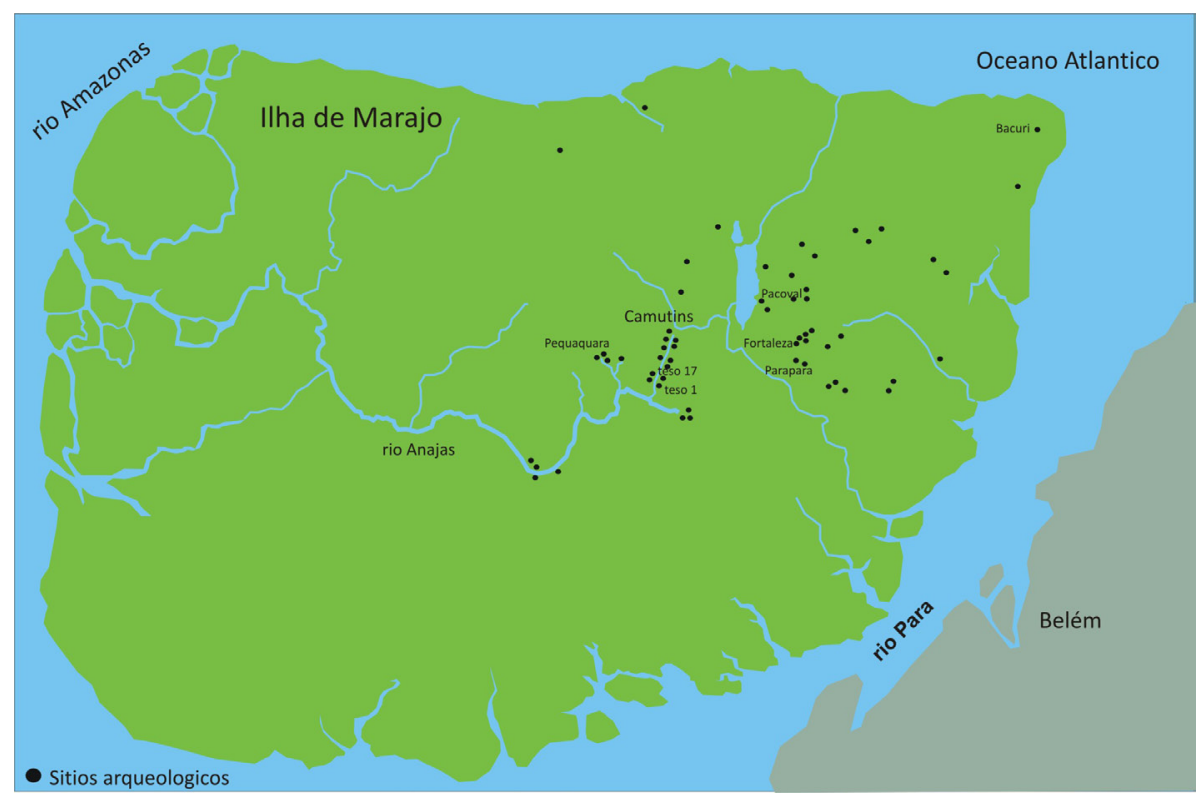

Figura 2 - Mapa da Ilha de Marajó com a localização dos sítios mencionados no artigo. 
médio. Um dos fragmentos (Figura 3-B) foi encontrado junto ao entulho (solo e fragmentos) escavados para a retirada de um sepultamento junto ao perfil 3. Possui $18 \mathrm{~cm}$ de diâmetro e seu assento é decorado com linhas incisas paralelas bem executadas e dispostas em bandas que se cruzam, lembrando uma peça têxtil ou de cestaria. Outro banco, com assento com $15,5 \mathrm{~cm}$ de diâmetro, sem decoração, e com perfuração central, foi encontrado durante a limpeza do perfil 1 (Figura 3-G). Os demais bancos na Figura 3 foram encontrados em coletas de superfície no teso 1-Camutins.

Entre os oito bancos encontrados no teso 17: Belém (Figura 4), três não são decorados; um desses fragmentos é de um banco com perfuração central. Aos 90-100 cm de profundidade, na escavação 1, foi encontrado um banco inteiro,

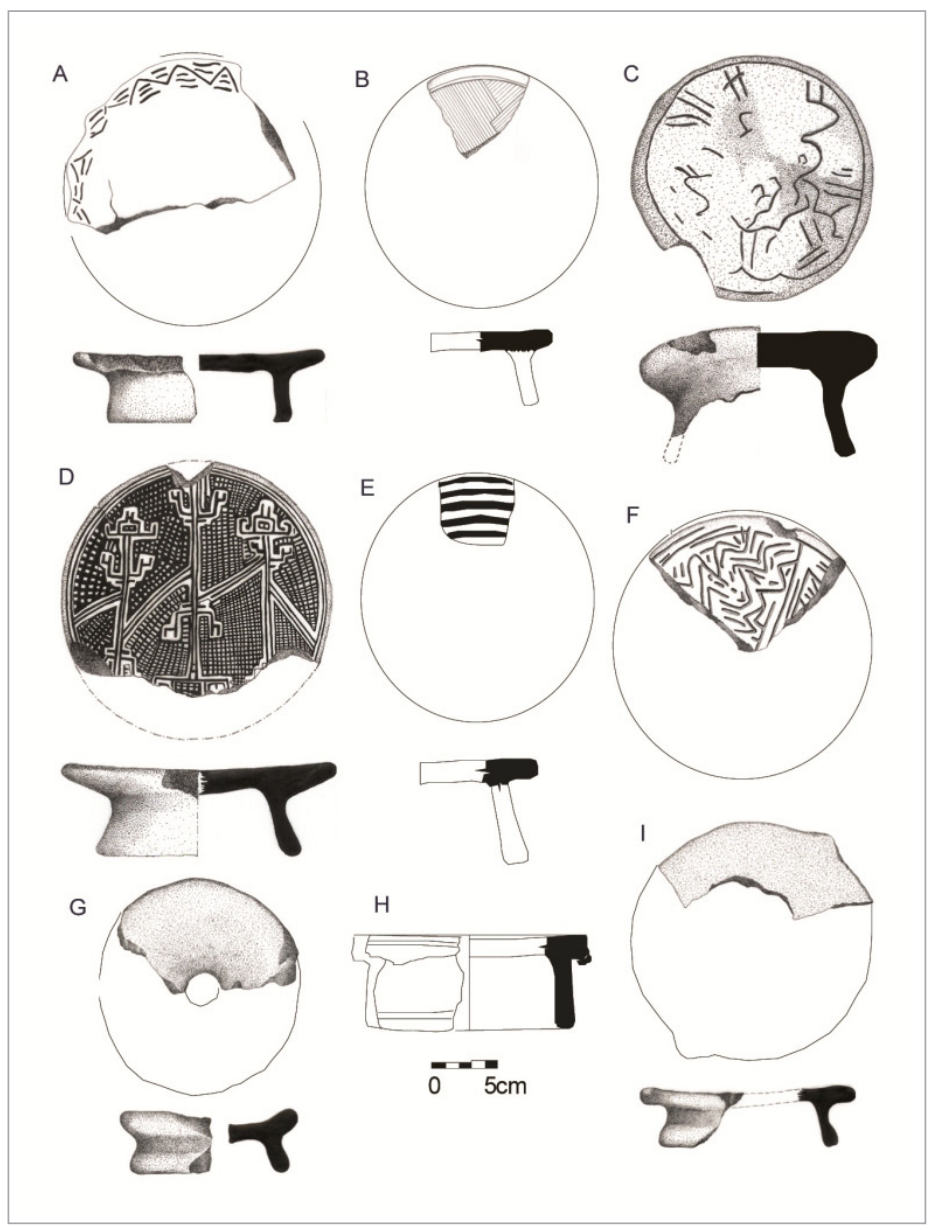

Figura 3 - Bancos coletados no teso 1 do sítio Camutins: (A) 2471-sup; (B) 2471-41; (C) 2471-163; (D)2471-7; (E) 2471-41; (F) 2471-132; (G) 2471-65; (H) 2471-7; (I) 2471-41, acervo MPEG, ilustrações de Raimundo Jorge Mardock. 
sem decoração (Figura 4-D). Essa área do sítio foi interpretada como uma área aberta, onde foram encontrados igualmente muitos fragmentos de tangas e remanescentes de produção cerâmica.

As técnicas decorativas preferidas entre os fragmentos de banco recolhidos nesse teso foram o guajará inciso (linhas duplas feitas com instrumento de duas pontas, Figura 4-E e 4-F), anajás simples inciso (Figura 4-H) e joanes pintado (Figura 4-G). O tamanho do assento variou entre 15 e $22 \mathrm{~cm}$ (mediana de 20 $\mathrm{cm}$, sendo 15 um outlier). Logo, os assentos dos bancos encontrados no teso 17 são maiores do que aqueles encontrados no teso 1. Bancos encontrados no teso 17 estavam na escavação 1 (área aberta), entre os níveis 50 e $100 \mathrm{~cm}$, na

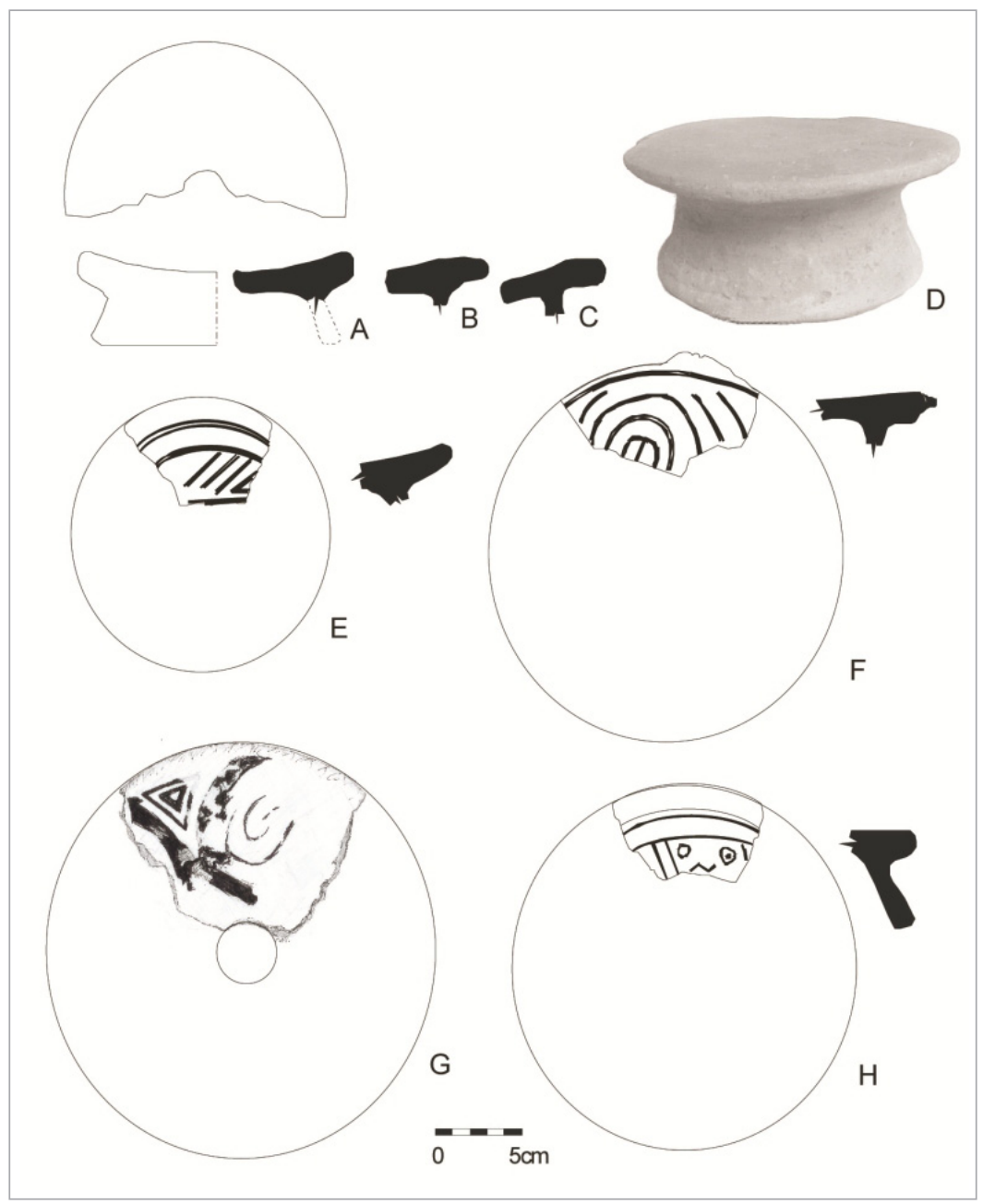

Figura 4 - Bancos coletados no teso 17:Belém, do sítio Camutins: (A) 260675;(B) 2606-53; (C) 2606-119; (D) 2606-42; (E) 2606-127; (F) 2606-381; (G) 2606-98; (H) 2606-409. Acervo MPEG, ilustrações de Denise Schaan. 
escavação 4 (topo do teso), entre os níveis 50 e $70 \mathrm{~cm}$, na lixeira, nível 105$115 \mathrm{~cm}$, e na área de sepultamentos, entre os níveis 30 e $80 \mathrm{~cm}$, mas não associados com nenhum sepultamento em particular (informações de procedência de todos os bancos mencionados nesse artigo estão no apêndice 2).

Comparando as amostras dos tesos $1 \mathrm{e}$ 17, é evidente a grande variabilidade em termos de decoração. Particularmente um banco do teso 1 mostra uma decoração excisa bastante elaborada (Figura 3-D), que contrasta com os bancos sem decoração presentes no teso 17 (Figra 4-A-D). Infelizmente, não é possível, na falta de outros indicadores, avaliar os possíveis significados sociais das diferenças observadas (Schaan 2004:335-338).

Durante prospecção realizada no alto rio Goiapi, sudeste da ilha de Marajó, em 2007, cinco fragmentos de bancos foram coletados na superfície do teso Casa Velha II (Sítio Fortaleza) e um no sítio Parapará (Figura 5). Todos os assentos são decorados com incisões e sem engobo (anajás simples inciso), alguns deles com motivo imitando trançados.

\section{OS BANCOS ESTUDADOS}

Para construir nossa reflexão sobre os bancos da fase marajoara nos valemos de dados produzidos em pesquisas quantitativas e qualitativas em acervos, que realizamos em diversos momentos. A segunda autora estudou coleções de bancos de museus, de 1994 a 2003, enquanto que a primeira autora estudou os bancos coletados durante o Projeto Goiapi (2007-2008) e realizou

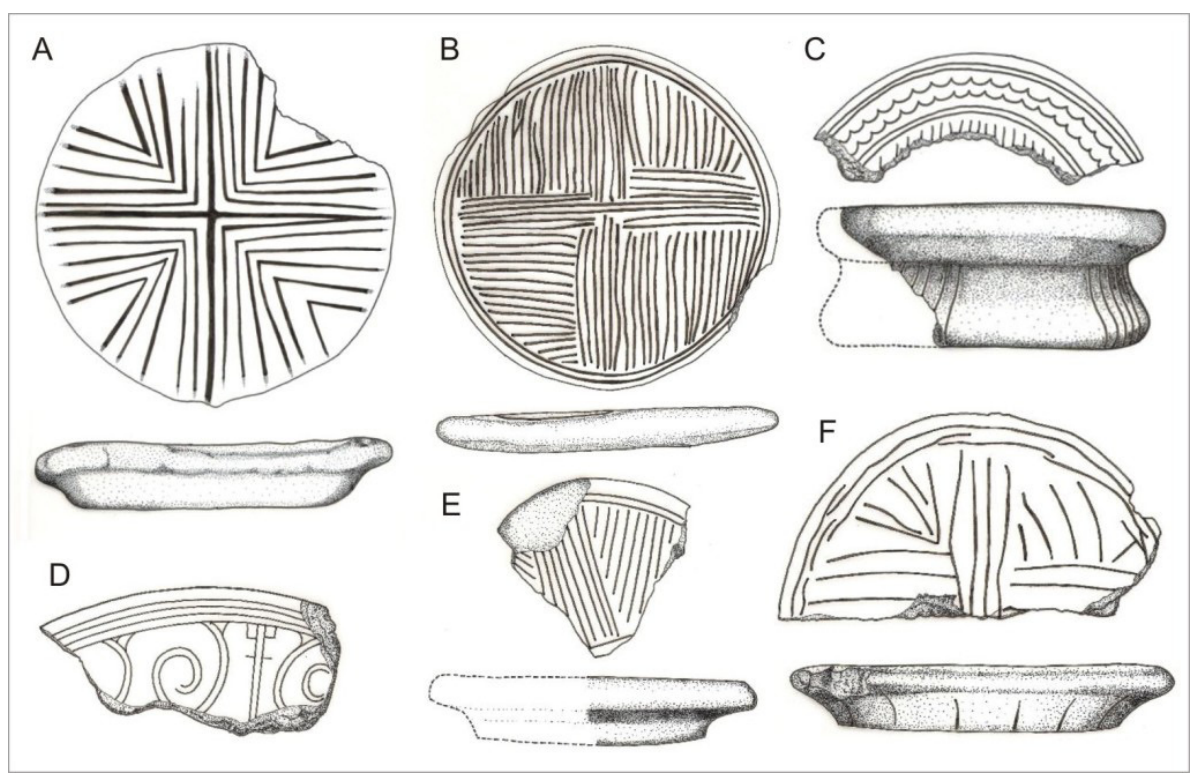

Figura 5 - Fragmentos de bancos e assentos de bancos provenientes do alto rio Goiapi: (A) JO37; (B) JO35; (C) JO37-46; (D) JO37-28; (E) JO37-147; (F) JO37-48. Acervo UFPA, ilustrações de Deise Lobo. 
a análise quantitativa (Alves 2009). A análise iconográfica seguiu a metodologia utilizada em outros trabalhos com a cerâmica marajoara (Schaan 1997a; b; 2001b; 2007).

Optamos por não priorizar uma amostra homogênea de bancos da fase marajoara, pois há muita variabilidade no tipo de informação que se pode obter dos bancos conhecidos.

Tivemos acesso a bancos e fragmentos de bancos provenientes de escavações em contextos bem documentados - nesse caso, tínhamos a vantagem do contexto, mas a desvantagem de que a maioria dos bancos eram apenas fragmentos e, nesse sentido, não tínhamos acesso a alguns dados quantitativos (como altura, quando o fragmento era de assento; ou diâmetro, quando o fragmento era de suporte), nem aos motivos decorativos completos. Por outro lado, tivemos acesso a objetos de coleções, sem informações de procedência, mas ao mesmo tempo com a possibilidade de examinar objetos inteiros em detalhe, medi-los e reproduzir sua decoração por completo. Por fim tivemos a possibilidade de observar bancos em catálogos e livros, mas sem a possibilidade de conhecer seus contextos ou medi-los. Para que nosso universo de pesquisa fosse o mais amplo possível, resolvemos utilizar todas estas fontes, com o devido cuidado de dar-lhes um tratamento diferenciado.

Os bancos estudados provêm dos seguintes acervos:

Acervo do Musen Universitário Oswaldo Rogrigues Cabral-UFSC - Possui dois (02) bancos inteiros, da Coleção Tom Wildi, sem procedência conhecida. Ambos possuem assento e suporte decorados com linhas incisas (Figura 7-B e 7-C). Acervo do Museu Paraense Emílio GoeldiMPEG - Possui 33 bancos ou fragmentos de bancos que provêm de doações e coleções de particulares, sem procedência, a maioria inteiros e em bom estado de conservação. Quatro bancos provêm das pesquisas de Simões e Figueiredo na década de 1960. Além disso, há 14 bancos ou fragmentos de bancos com procedência conhecida coletados durante escavações no alto rio Anajás (Schaan 2004). O levantamento das coleções sem indicação de sítio de procedência foi realizado entre 1997 e 1999. Diversos desses bancos faziam parte da coleção da Fazenda São Marcos, adquirida pelo Governo do Estado do Pará em 1982 e depositada no $\mathrm{Mu}-$ seu Goeldi. A Fazenda São Marcos se localiza no curso superior do rio Camutins. É possível que essas peças tenham sido coletadas nos tesos Cuieiras e Furinho, que ficam dentro da área da fazenda (escavações nesses sítios foram relatadas em Hilbert 1952). Entretanto, sabese que no Marajó é comum as pessoas se presentearem umas às outras com peças de cerâmica. Por isso, alguns podem ter vindo de outros locais da ilha. O estudo do material coletado durante as escavações realizadas entre 1999 e 2002 em sítios do rio Anajás foi concretizado em 2003. Todos os bancos e fragmentos do MPEG foram desenhados por Raimundo Jorge Mardock. Acervo do Museu do Marajó (MdM) - A coleção de bancos do Museu do Marajó 
é formada por três bancos, dois fragmentos de bancos e três assentos de bancos, todos provenientes de doações, sem procedência conhecida. Apenas um dos bancos está preservado completamente, o restante possui preservação incompleta. O acervo foi estudado quando Denise Schaan foi curadora daquele museu, entre 2005 e 2008. Fotografias desses bancos estão disponíveis no livro Cultura Marajoara (Schaan 2009).

Acervo da Universidade Federal do ParáPossui seis fragmentos de bancos provenientes de prospecções realizadas no âmbito do Projeto Goiapi, quando foram realizadas escavações e prospecções em nove sítios da região do alto rio Goiapi na porção oriental da Ilha de Marajó. O teso da Casa Velha II do sítio Fortaleza foi escavado em dezembro de 2007, e o teso Parapará foi prospectado em 2005. Desses dois sítios são oriundos os assentos e o fragmento de banco que fazem parte da coleção do projeto, sob guarda da Universidade Federal do Pará - UFPA. Todos possuem preservação incompleta (Figura 5).

Acervo Fazenda São Marcos - Um banco com decoração antropomorfa foi fotografado na sede da fazenda São Marcos por Schaan em 1999, e posteriormente desenhado por Deise Lobo a partir da fotografia (Figura 15). Não foram tiradas medidas e não há informações de procedência, ainda que seja provável que provenha dos tesos Furinho e Cueiras, localizados próximos à sede da Fazenda.

Acervo do Banco Santos - Incluímos na análise dois bancos da Coleção Banco Santos, hoje sob a guarda do MAEUSP. Ambos foram desenhados a partir de fotografias e possuem decoração incisa (Figuras 11-C e 17-C).

A análise quantitativa foi realizada em uma amostra de 69 bancos ou fragmentos de bancos, em diferentes estados de preservação, sendo 45 bancos provenientes de doações e 24 de pesquisas arqueológicas. O fato de que $65 \%$ dos bancos provêm de doações, portanto sem informações sobre a procedência exata, dificulta o entendimento de seu uso a partir do sítio arqueológico. Portanto, o estudo dos contextos repousa sobre $35 \%$ da amostra.

Foram estabelecidas quatro categorias para classificar os bancos quanto ao seu estado de preservação: inteiros, semiinteiros, fragmentos, fragmento de assento. Quarenta e quatro bancos (64\%) estão inteiros ou semi-inteiros.

Quanto à forma, os bancos possuem em sua maioria assento circular, com duas exceções, em que se encontram a forma quadrangular (um banco) e oval (um banco). Apenas um fragmento não permitiu inferir a forma do assento.

Cinco bancos possuem furo central: dois sem decoração, provenientes do sítio Camutins (Figuras 3-G e 4-A), um do tipo joanes pintado, proveniente também do sítio Camutins (Figura 4-G) e dois do tipo pacoval inciso (Figura 9-A e 9-C), de sítio de procedência desconhecida. O banco da Figura 10-E, coletado por Nimuendajú no teso Bacuri também possui furo central. Essa é uma ocorrência rara e não encontramos na literatura etnográfica nenhuma informação sobre uso de bancos com essa característica. 
Quando ao tratamento de superfície, os bancos dividem-se em decorados (com decoração plástica, engobo ou pintura sobre o assento ou a parede externa da base anelar), e sem decoração. Os bancos sem decoração são alisados, mas em geral o acabamento é tosco. Quanto à técnica decorativa, observou-se a ocorrência de nove tipos decorativos (dos 15 definidos para a cerâmica da fase marajoara, ver apêndice 1). Para identificar a técnica decorativa utilizamos a tipologia de Meggers \& Evans (1957), pois a mesma dá conta de todo o tratamento de superfície aplicado sobre os objetos.

Realizamos o cruzamento de dados como decoração, altura e diâmetro (Quadro I). $\mathrm{O}$ diâmetro do assento varia de 8,8 a $26 \mathrm{~cm}$, com média de $14,89 \mathrm{~cm}$ e mediana de $14 \mathrm{~cm}$. Portanto os bancos do sítio Camutins são em geral maiores do que a média. A altura varia entre 3 e $11 \mathrm{~cm}$, com
$5,68 \mathrm{~cm}$ de altura em média e mediana de $5 \mathrm{~cm}$. Dos 69 bancos da amostra, não foi possível medir a altura de 22.

Em 45\% da amostra (31 bancos), a técnica decorativa preferencial é o anajás simples inciso, que consiste em linhas incisas retilíneas, na maioria dos casos. Contando com as demais técnicas incisas, são 44 bancos ou $64 \%$ da amostra com o uso de decoração incisa, o que faz dessa técnica a preferida. A análise da iconografia indica que a preferência pelo uso dessa técnica em muitos casos pode se relacionar à intenção de representar motivos da cestaria.

Talvez pelo pequeno tamanho da amostra não seja aparente uma possível relação entre tamanho e técnica decorativa. Os bancos decorados com a técnica pacoval inciso e com furo central possuem o maior diâmetro, mas também há bancos com assento grande entre aqueles decorados apenas com incisões (Quadro I).

Quadro I

Decoração, diâmetro do assento e altura em cm em 55 bancos

\begin{tabular}{l|c|c|c|c}
\hline \multicolumn{1}{c|}{ Tipo } & Quantidade & $\begin{array}{c}\text { Diâmetro } \\
\text { Médio }\end{array}$ & $\begin{array}{c}\text { Variação } \\
\text { Diâmetro }\end{array}$ & $\begin{array}{c}\text { Altura } \\
\text { Média }\end{array}$ \\
\hline Anajás branco Inciso & 2 & 12,25 & $12-12,5$ & 6,25 \\
\hline Anajás simples inciso & 31 & 15,83 & $9-26$ & 5,96 \\
\hline Anajás vermelho inciso & 7 & 14,56 & $9,2-21$ & 5,78 \\
\hline Arari com engobo duplo exciso & 1 & 11,5 & 11,5 & 5 \\
\hline Arari simples exciso & 5 & 13,15 & $8,8-22,5$ & 4,9 \\
\hline Arari vermelho exciso & 5 & 14,2 & $8,8-20,5$ & 7,15 \\
\hline Guajará inciso & 3 & 18 & $15-21$ & 0 \\
\hline Joanes pintado & 3 & 17,5 & $14-21$ & 4,5 \\
\hline Pacoval inciso & 2 & 25,25 & $24,5-26$ & 10,3 \\
\hline Sem decoração & 10 & 16,23 & $11-23,2$ & 5,3 \\
\hline Total & 69 & 14,89 & & 5,68 \\
\hline
\end{tabular}




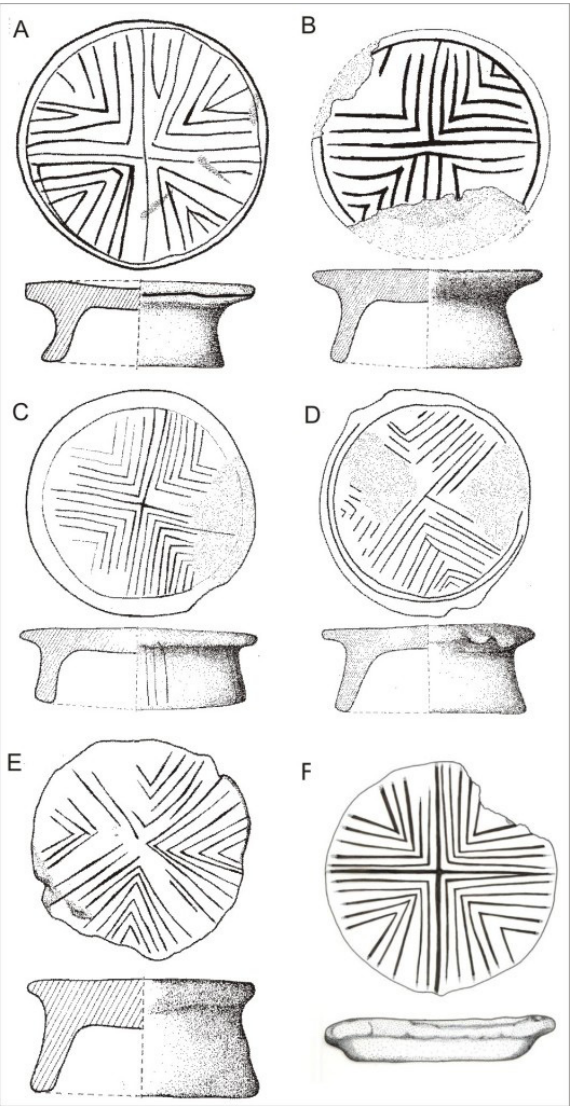

Figura 6 - Bancos com decoração incisa: (A) 2279; (B) 138; (C) 2119; (D) 33; (E) 143; (F) JO37. Acervo MPEG (A-E) e UFPA (F). Ilustrações de Raimundo Jorge Mardock (A-E) e Deise Lobo (F).

\section{A ICONOGRAFIA DOS BANCOS ESTUDADOS}

A decoração "anajás simples inciso", que predomina em nossa amostra, guarda semelhanças com a decoração dos bancos de madeira dos tukano. São em geral incisões retilíneas paralelas dentro de campos decorativos delimitados por incisões. O primeiro padrão que queremos destacar é o da Figura 6, em que o assento circular é dividido em quatro partes iguais, por duas linhas que se cruzam no centro do círculo. Cada uma dessas quatro partes é formada por duas linhas formando um vértice de 90 graus a partir do centro e que se estendem até o perímetro do assento, em alguns exemplares marcado por linha incisa a cerca de meio centímetro da borda. Cada um dos quatro campos decorativos é preenchido por vértices de 90 graus ou menos, formando "V"s paralelos.

Um padrão bastante popular em bancos, mas encontrado raramente em outros objetos de cerâmica são feixes de linhas paralelas que se cruzam representando trançados feitos de fibras vegetais ou tecidos (Figura 7). Tais desenhos estariam imitando motivos da cestaria, como os bancos desâna (família lingüística tukano) que possuem o assento pintado em preto e branco com motivos semelhantes (McEwan 2001: 184, fig. 7.10).

Para os tukano tais motivos "simbolizam os banquinhos de madeira dos homens, que são ornados dessa forma" (ReichelDolmatoff, 1976:87); o banco denota "introspecção e estabilidade" (ReichelDolmatoff 1976:33). Os informantes de Vincent (1987), no rio Papuri, disseram que é "o caminho dos cupins" representando sua passagem do mundo subterrâneo para a superfície terrestre, comparada à viagem de seus heróis míticos pelos vários níveis do universo. A técnica de decoração por incisões não se restringe, entretanto, às linhas retas. Em nossa amostra identificamos um tipo de decoração em linhas curvas formando espirais e volutas (Figura 8). O motivo decorativo (Figura 8-A) representa uma face sorridente; uma icono- 


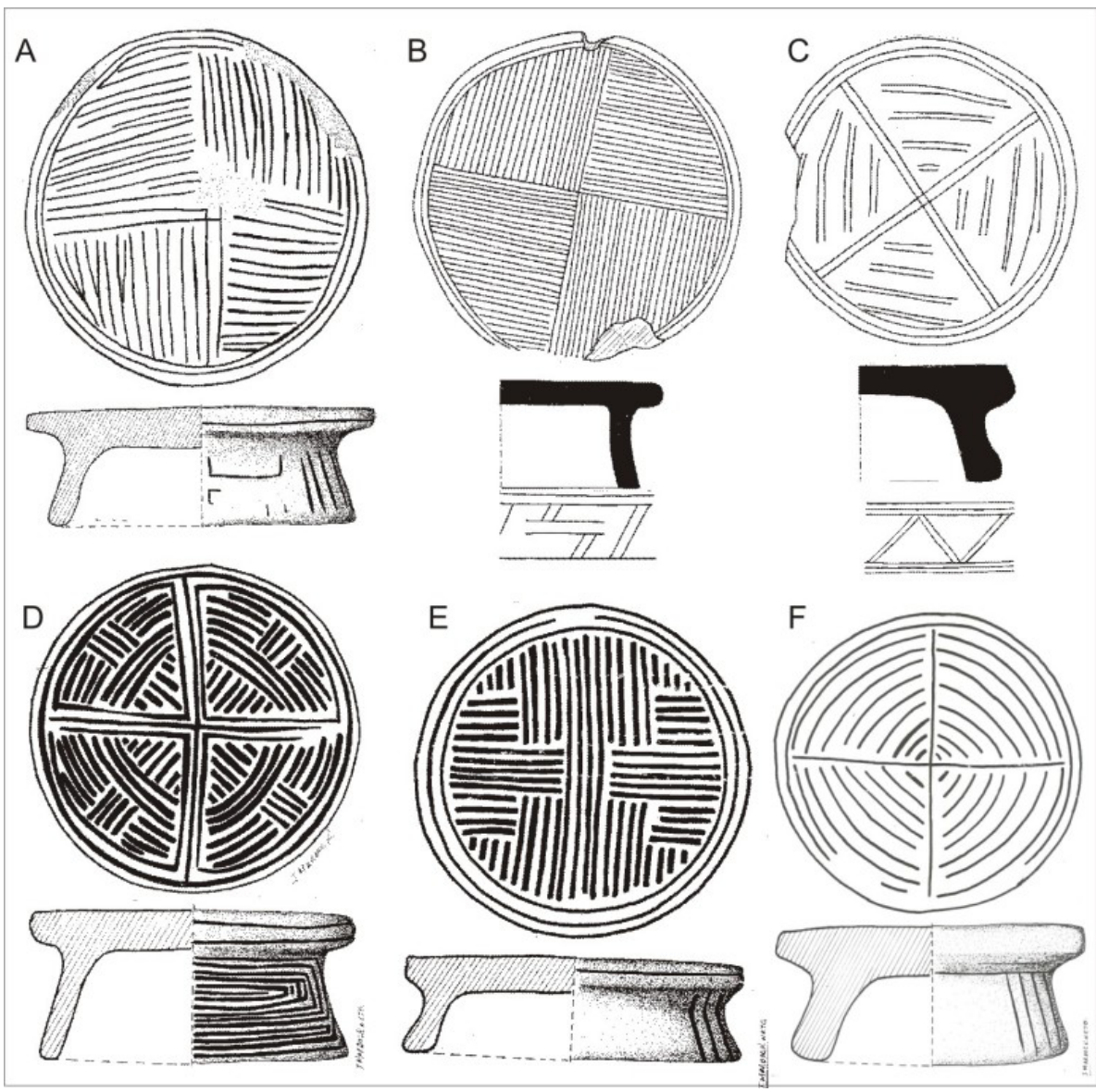

Figura 7 - Bancos com decoração incisa, imitando trançados: (A) 2386; (B) TWSP-30; (C)TWSP-23; (D) 135; (E) 2267; (F) 2268. Acervo MPEG (A, D-F) e Museu UFSC (B, C). Ilustrações de Raimundo Jorge Mardock (A, D-F) e Denise Schaan (B, C).

grafia que está presente no bojo de urnas funerárias. Aqui o motivo se repete espelhado em duas metades do assento, como se os "queixos" das duas metades estivessem se tocando. Está presente aqui o "T", um signo que nas urnas funerárias antropomorfas é encontrado entre os olhos, representando ao mesmo tempo o nariz e as sobrancelhas (Schaan 2007a). Similar é o motivo no assento do banco da Figura 8-C, só que aqui os "T"s são substituídos por figuras trian- gulares. Nos assentos dos bancos das Figuras 8-B e 8-D, a posição das volutas se inverte. Nos bancos tukano, o motivo central do banco 8-B representa as duas metades exogâmicas (Ribeiro 1992). Os limites do campo decorativo que na Figura 8-A são ornados com "T"'s, aqui é preenchido com espirais ou volutas. Espirais na iconografia marajoara geralmente representam cobras (Schaan 1997a). Ornatos zoomorfos completam a decoração desses dois bancos junto às 
bordas dos assentos. No banco da Figura 8-D está representada a cabeça de uma ave. No banco da Figura 8-B protuberâncias nos lados do assento também sugerem representação zoomorfa, como as encontradas nas espinhas dorsais de jacarés em urnas funerárias.

Os dois bancos maiores de nossa amostra, com altura de $10 \mathrm{~cm}$ e diâmetro de assento de 24,5 (Figura 9-A) e $26 \mathrm{~cm}$ (Figura 9-C) são decorados com o estilo pacoval inciso e possuem o centro do assento perfurado. $\mathrm{O}$ motivo decorativo também está presente em urnas funerárias. A cruz é comum na iconogra- fia marajoara, mas não sabemos o que representa. O banco da Figura 9-B possui furo de menor diâmetro e pintura, uma técnica decorativa rara em bancos.

Encontramos ainda na amostra estudada representações que interpretamos como zoomorfas à luz dos estudos da iconografia marajoara (Schaan 1997; 2001; 2009). Um tema clássico é a representação do couro da cobra (Figura 10). Nimuendaju (2004) coletou um fragmento de banco no teso Bacuri que possui no suporte uma representação realista em relevo de uma cobra cujo corpo está ornado com losangos

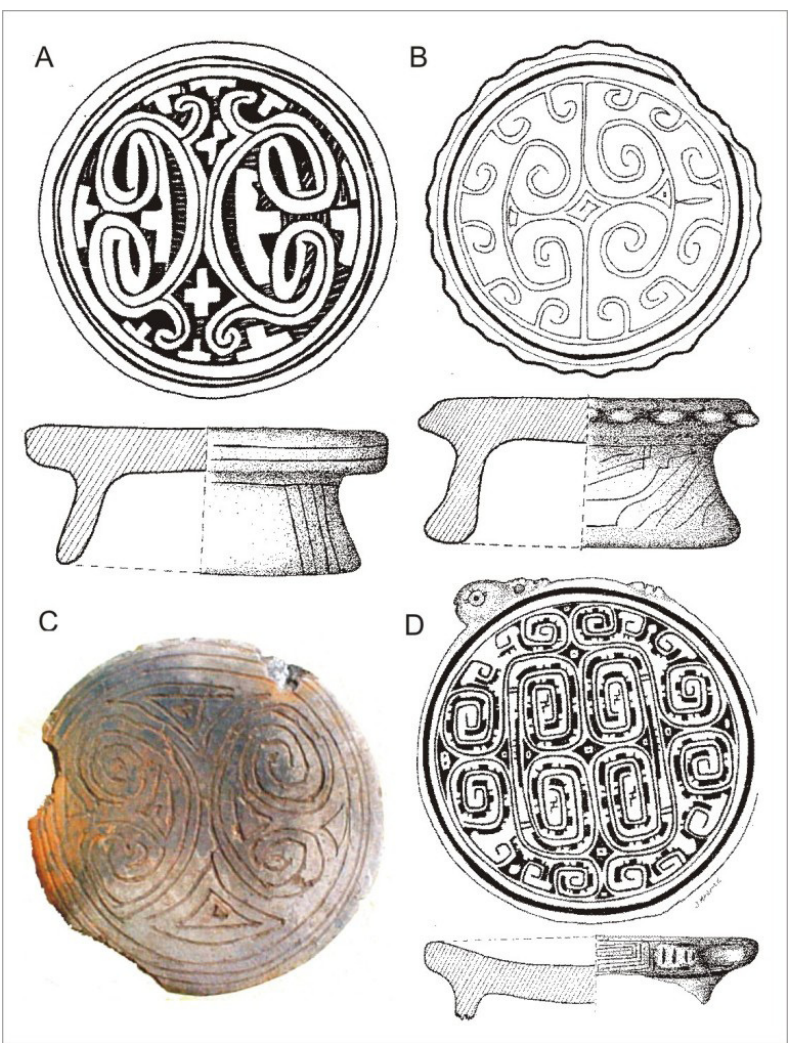

Figura 8 - Bancos com decoração excisa e incisa, representando faces ou metades complementares: (A) 2269; (B) 141; (C) 2416-1; (D) 225. Acervo do MPEG. Ilustrações de Raimundo Jorge Mardock. Fotografia de Denise Schaan 


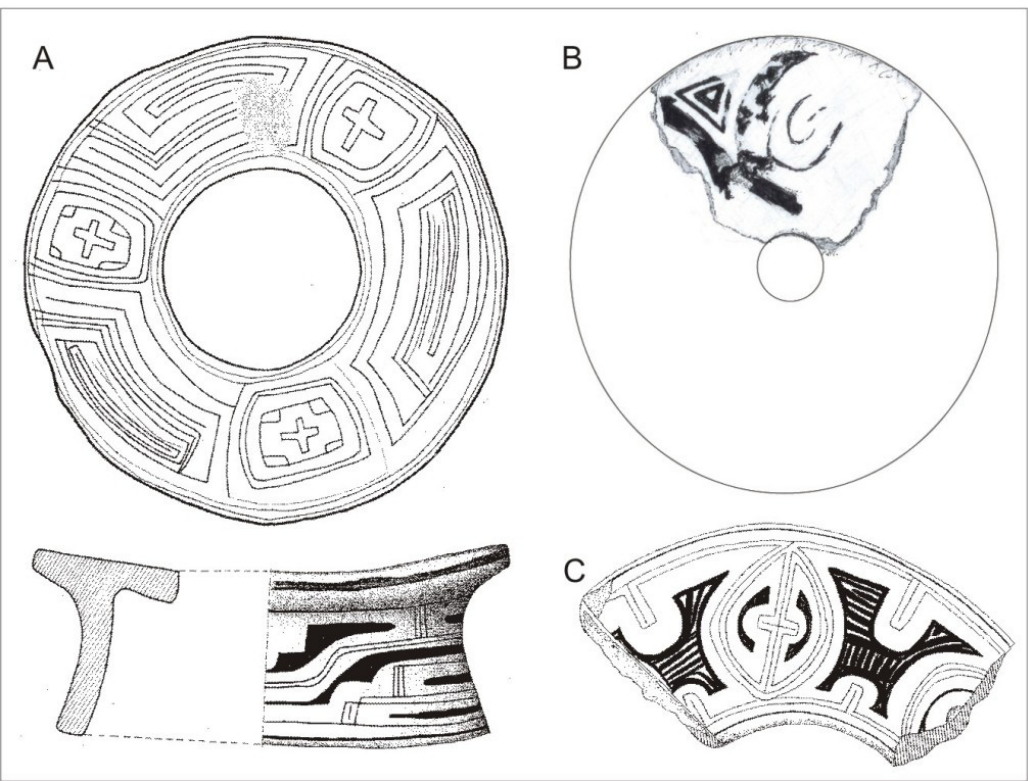

Figura 9 - Bancos com furo central: (A) 128; (B) 2606-98; (C) 1792. Acervo do MPEG (A e C) e UFPA (B). Ilustrações de Raimundo Jorge Mardock (A) e Denise Schaan (B e C).

e triângulos (Figura 10-E). A partir da ocorrência dessas representações realistas, Schaan tem interpretado os motivos decorativos do couro da cobra em outros contextos como a representação metonímica da própria cobra, um ser mítico ancestral extremamente importante na cosmologia marajoara no passado e no presente (Schaan 2007; 2010; Schaan e Rodrigues no prelo). Essas representações, em geral, ocorrem na forma de bandas junto às bordas de vasos e pratos, ou em faixas, como ocorre nos bancos da Figura 3-A e $\mathrm{B}$, ou ainda ocupando todo o campo decorativo como é o caso dos bancos B e C, na Figura 10. Na Figura 10-D, o motivo em espirais representa cobras enroladas, uma representação dualista comum em outros objetos de cerâmica da fase marajoara. Já no banco da Figura 10-F, as linhas paralelas hachuradas representam o lado ventral da cobra. (Schaan 1997a).

Além das cobras, encontramos nos bancos a representação da carapaça do jabuti, presente ocasionalmente em fundos de pratos (Figura 11). Nos bancos A e C da Figura 11 a representação é bastante clara. As incisões sobre o assento do banco da Figura B foi executado de forma descuidada, por alguém com pouca destreza, o que temos percebido em outros bancos. Já no caso do banco da Figura 11-D não temos toda a decoração presente para avaliar. De toda a maneira os motivos decorativos dos bancos B e D, apesar da semelhança com A e C, são espirais, e não círculos concêntricos, portanto não fica claro se também represen- 


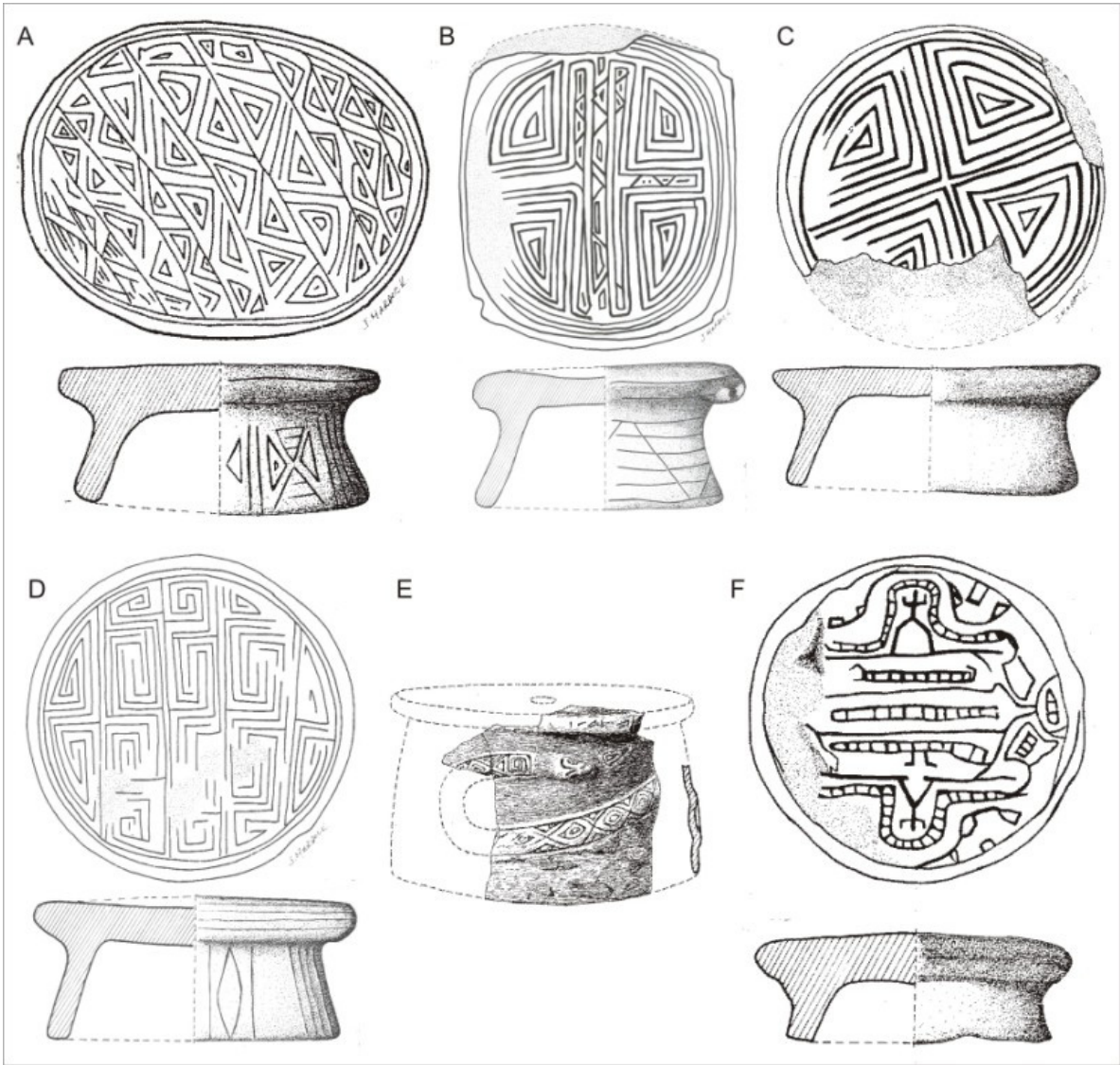

Figura 10 - Representação de cobras sobre bancos: (A) 2291; (B) SR-02; (C) 137; (D) 134; (E) Nimuendaju 2004, plate 017; (F) 142. Acervo MPEG (A-D;F); Museum of World Cultures, Gothenburg(E). Iustrações de Jorge Raimundo Mardock para os bancos do acervo do MPEG.

tariam a carapaça do jabuti, ou a cobra, flechas e de cujos cantos saem trigeralmente representada por espirais. dentes. As flechas na iconografia Representações zoomorfas estão presentes também nos bancos da Figura 12. Apesar das diferenças aparentes entre as iconografias dos três assentos, seu conteúdo estrutural é semelhante. Observando as Figuras 12-A e B vemos que há uma figura central formada por um retângulo de cujos lados saem marajoara representam a cabeça da Bothrops atrox, uma espécie de cobra bastante freqüente na fauna local que encontra sua representação na iconografia por meio de sua peculiar cabeça triangular (Roosevelt 1991; Schaan 1997a; b). Já os tridentes são utilizados na iconografia para representar as patas do jacaré, outro animal freqüente na fauna e 
na iconografia. A figura zoomorfa assim representada poderia também representar dois jacarés sobrepostos (ver exemplos em Carvalho 1975; Schaan 1997a). No restante do campo decorativo encontramos pequenos ícones que estão presentes também sobre couro de cobras, portanto, seriam igualmente metonímias desse ser mitológico. No caso do banco B trata-se da representação de dois bastonetes verticais e paralelos no interior de um retângulo; e no caso do banco A são as representações foliáceas. Já no banco $C$ a representação do jaca-

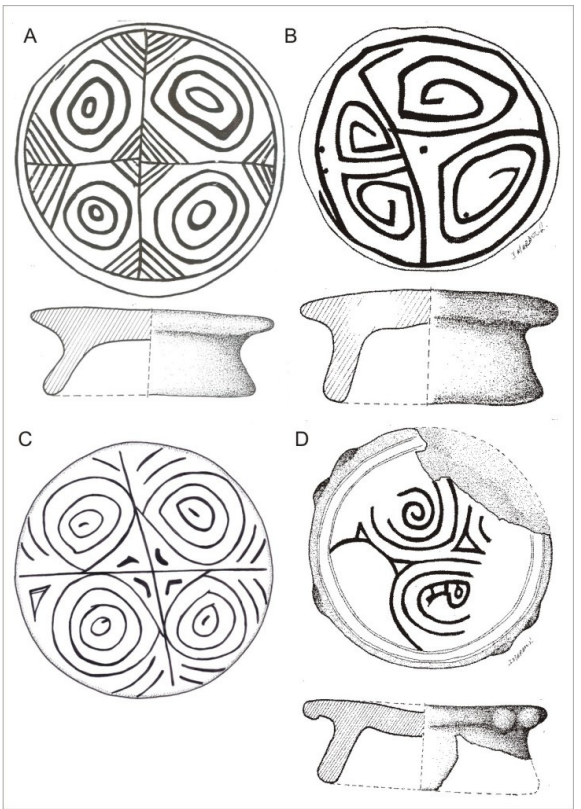

Figura 11 - Motivo imitando a carapaça do jabuti sobre assentos de bancos: (A) SR-01; (B) 136; (C) GRT 131; (D) 122. Acervo MPEG (A-B,D); Acervo MAEUSP (C). Ilustrações de Raimundo Jorge Mardock (A-B, D) e Deise Lobo (C). ré é mais clara. Como no caso do prato que é a capa do livro "A Linguagem Iconográfica da Cerâmica Marajoara" (Schaan 1997a), aqui também o tridente que deveria estar representando as patas está no lugar da cabeça e do rabo. Esses bancos, portanto, trazem a representação icônica do jacaré ancestral, um personagem importante da mitologia marajoara que pode ser exclusivo de um dos clãs, o que é corroborado por sua representação em urnas funerárias e em tangas. Há que se observar ainda que os bancos A e B trazem representações zoomorfas em relevo tanto na lateral do assento como sobre o suporte, onde se encontram patas.

Outras representações icônicas de cobras e jacarés aparecem nos bancos da Figura 13, onde os motivos decorativos foram incisos de forma menos cuidadosa. No banco A, as linhas duplas hachuradas representam o lado ventral da cobra; talvez devido à presença dos tridentes e triângulos, essa iconografia represente um encontro desses dois seres mitológicos. No banco B, o campo decorativo é dividido em quatro, por duas linhas paralelas hachuradas (o lado ventral/ escamas) cujas pontas são finalizadas por tridentes. Dentro dos quatro campos decorativos assim delimitados encontra-se o motivo das cobras entrelaçadas, formadas por duas semi-espirais, 

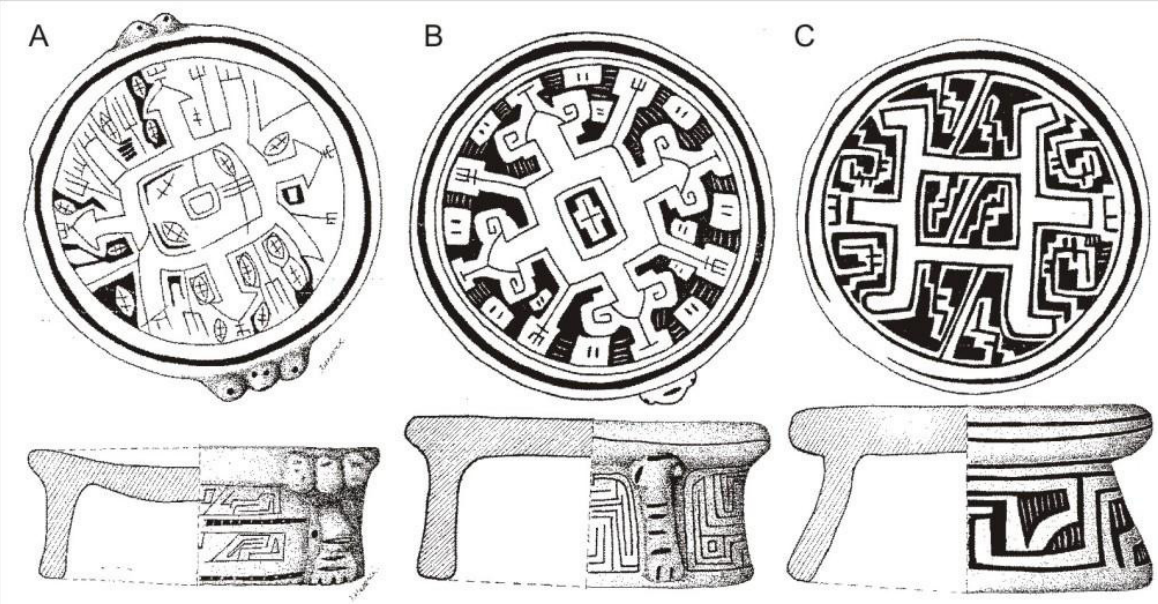

Figura 12 - Representação do jacaré sobre bancos: (A) 130; (B) SR03; (C) 2274. Acervo MPEG. Ilustrações de Raimundo Jorge Mardock.

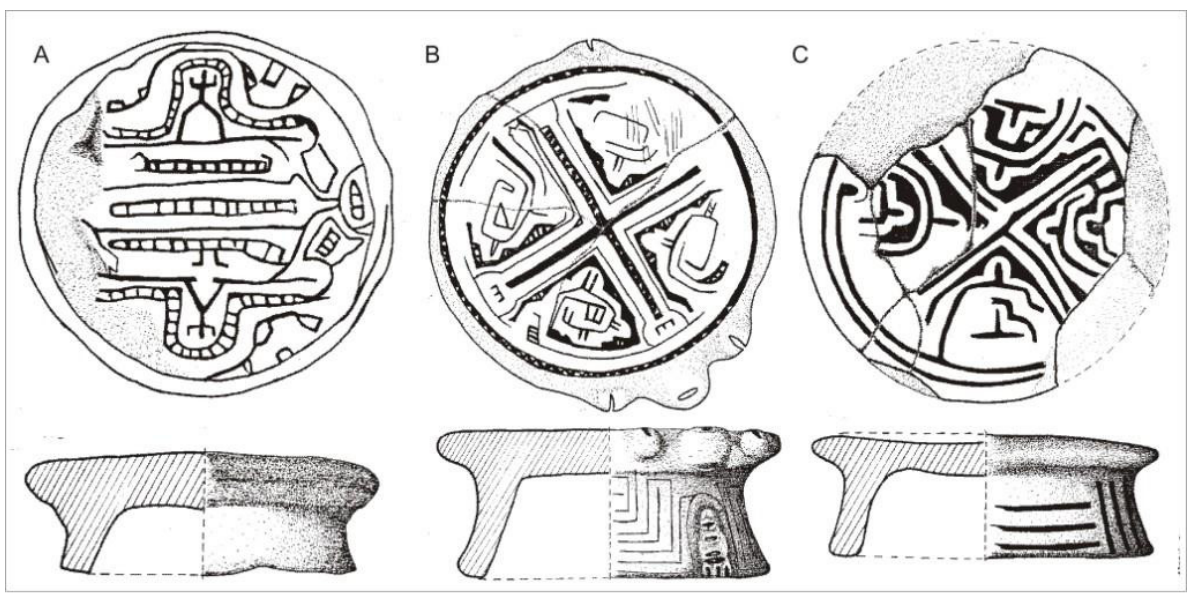

Figura 13 - Ícones de cobras e jacarés: (A) 142; (B) 140; (C) 1064. Acervo MPEG. Ilustrações de Raimundo Jorge Mardock.

um ícone popular na iconografia marajoara. No banco $\mathrm{C}$ também o campo decorativo está dividido em quatro, e no interior dessas divisões estão presentes os "Ts" que são encontrados sobre testas de figuras antropomorfas. No banco B estão presentes novamente as patas zoomorfas sobre o suporte. A decoração elaborada de alguns bancos contrasta com a produção menos cuidadosa de outros tanto em termos de sua forma quanto decoração que, juntamente com o desgaste da superfície, em alguns exemplares, dificulta a inter- 


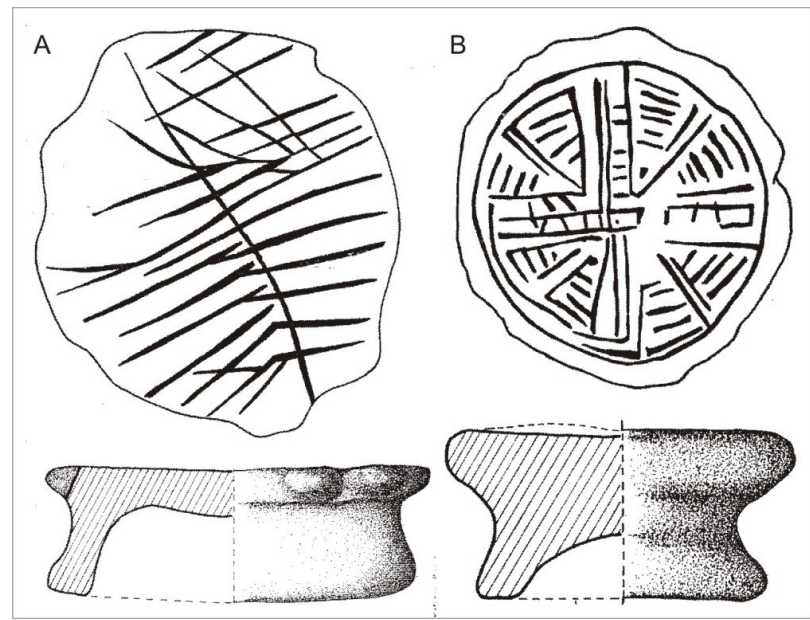

Figura 14 - Decorações menos elaboradas: (A) 139; (B) 144. Acervo MPEG. Ilustrações de Raimundo Jorge Mardock.

pretação de sua iconografia. Assim temos os bancos da Figura 14. Ambos poderiam fazer parte do conjunto dos bancos da Figura 7, mas seu estado de preservação torna difícil uma classificação.

Temos em nossa amostra um único banco antropomorfo (Figura 15). Assim como em outros casos reportados na literatura, há uma face humana representada sobre o suporte. É possível que esse banco fosse pintado, mas sua superfície encontra-se muito patinada. Não foi observado por muito tempo, pois foi fotografado na Fazenda São Marcos e posteriormente desenhado por Deise Lobo. A representação segue o padrão identificado no pescoço de algumas urnas funerárias encontradas em sítios próximos à Fazenda São Marcos, sítio Camutins. $O$ nariz é representado em relevo e pode funcionar como alça. Os olhos na forma de protuberâncias circulares são con- tornados por um filete que no canto dos olhos termina como uma lágrima. Olhos humanos na cerâmica marajoara são frequentemente circundados por escorpiões estilizados ou por cobras. A boca, também em relevo, é representada como uma meia-lua.

Por fim temos os bancos sem decora-

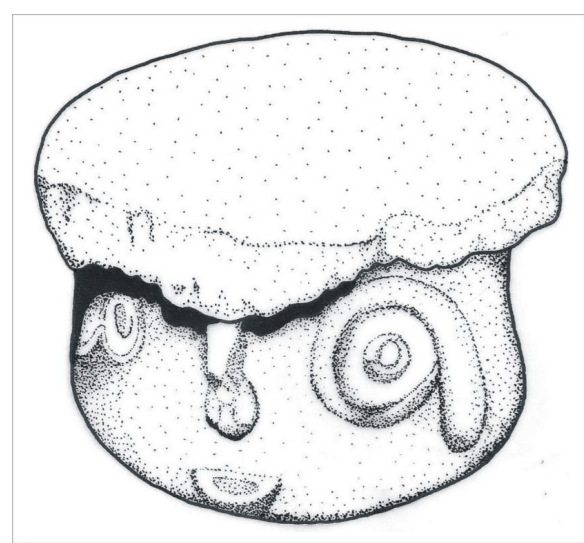

Figura 15 - Banco com representação antropomorfa. Acervo Fazenda São Marcos. Ilustração de Deise Lobo sobre fotografia de Denise Schaan. 


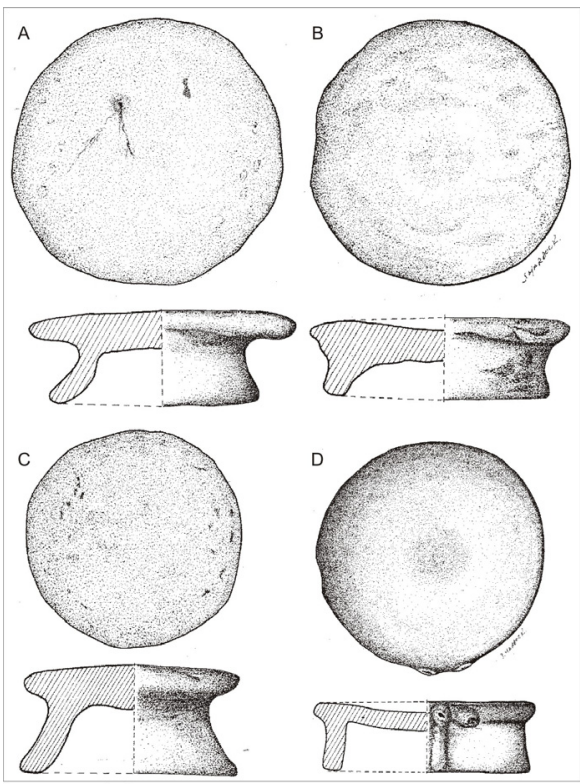

Figura 16-Bancos sem decoração: (A) 1353; (B) 133; (C) 1354; (D) 131. Acervo MPEG. Ilustrações de Raimundo Jorge Mardock.

ção, onde o tratamento de superfície se resume ao alisamento, muitas vezes descuidado. A Figura 16 mostra alguns exemplos, onde podemos observar que há também desleixo no formato da peça, o que pode significar que foram produzidos para finalidades mais mundanas do que aquelas comumente supostas com base na etnografia.

\section{CONSIDERAÇÕES FINAIS}

O estudo dos bancos da fase marajoara, tanto nos seus aspectos iconográficos, quanto contextuais, produziram dados interessantes. Nota-se inicialmente, que a estética dos bancos em geral é muito "simples", se compararmos à exuberante decoração de outros objetos, como urnas, vasos e pratos. No entanto, lem- bramos que em contextos funerários da elite marajoara tem sido encontrados objetos com decoração singela ou até sem decoração - como tangas sem decoração e vasinhos incisos (com decoração semelhante aos bancos) - no interior ou ao lado de urnas ricamente decoradas (Schaan 2003). Objetos de prestígio, por sua raridade, como contas de colar e lâminas de machados líticos, também tem sido encontrados dentro de urnas funerárias sem decoração (Schaan 2004). Uma vez que os sepultamentos em urnas funerárias são encontrados somente em alguns tesos e que apenas uma pequena parte da sociedade merecia tal tratamento, entende-se que eram contextos funerários da elite. Portanto, decorações "simples" para nossos padrões não necessariamente indicariam usos menos especiais para estes objetos.

A decoração predominante dos bancos - o uso do motivo da cestaria - com incisões, segue padrões etnográficos e se relaciona à idéia de suporte, de algo a ser colocado sobre o chão, como uma esteira, um tapete que protege do contato com a terra (McEwan 2001: 184). Ainda o fato dos bancos serem encontrados somente nos tesos de elite reforça seu uso por essa parcela da sociedade, com o caráter de exclusividade que a etnografia lhe indica. Por outro lado, a ausência dos bancos no contexto funerário, seja como objeto associado aos sepultamentos ou presente na iconografia de urnas funerárias lhes sugere um uso mais mundano. Sugerimos que os bancos eram usados por membros da elite em vários contextos, talvez não somente como objetos para sentar. Uma possi- 
bilidade seria de que os bancos fossem usados em outros tipos de contextos rituais que não o funerário.

Nos princípios do século $\mathrm{XX}$, um rito de passagem de um povo de língua aruak que vivia nas florestas altas do Peru foi observado por etnógrafos:

"Meninas adolescentes da etnia Chama, ao atingirem a puberdade, eram reunidas durante a lua cheia, ocasião em que mulheres e homens adultos dançavam e bebiam líquidos servidos em potes zoomorfos até o amanhecer. $\mathrm{Na}$ manhã seguinte as meninas eram pintadas, drogadas com bebida e então cada uma deitava em um banco para que uma mulher mais velha cortasse seu clitóris e grandes lábios e os enterrasse. Em outra ocasião foi observado que a adolescente era deflorada com um pênis de argila, que representava seu noivo. Depois disso, as garotas eram mantidas isoladas em suas cabanas por um mês, vestindo uma peça de cerâmica de forma oval [grifos nossos] pra cobrir a região pubiana" (Métraux 1948) 3 .

Tal acontecimento, caso tivesse se passado na ilha de Marajó, poderia explicar a ocorrência de objetos de cerâmica como as tangas, potes zoomorfos, bancos, e uma espécie de "dedal" (Figura 17) que foi descrita por Morales-Chocano (comunicação pessoal 2008) como um "deflorador".

Assim como as estatuetas da fase marajoara, cuja diversidade indica seu uso polissêmico e possivelmente ritual (Schaan 2001a), os bancos parecem pertencer à mesma categoria de objetos cujo uso pode ter sido mais amplo do que somos levados a supor. Isso coloca uma dificuldade adicional na interpretação de objetos da cultura material arqueológica, mas ao mesmo tempo nos permite ampliar o leque de explanações possíveis.

É possível que no futuro outros objetos sejam escavados e tanto a iconografia quanto os contextos arqueológicos nos proporcionem novos dados sobre os bancos da fase marajoara. Por ora, nos parece que os dados indicam que eram objetos usados em contextos diversos, não somente para sentar e não relacionados unicamente a contextos de hierarquia e poder.

\section{NOTAS}

1 Vasos cerâmicos antropomorfos onde estão também representados bancos são encontrados na cerâmica da fase Santarém (Gomes 2001), Maracá (Guapindaia 2001) e outras culturas do baixo Amazonas (McEwan 2001).

${ }^{2}$ Utilizamos os tipos cerâmicos da fase marajoara definidos por Meggers e Evans (1957:324-270) para descrever a decoração dos bancos. Essa tipologia pode ser encontrada no apêndice 1 desse artigo.

${ }^{3}$ Traduzido do inglês: "Tessmann (1928 e 1930) reports that a group of pubescent Chama girls were assembled at full moon while men and women danced all night and drank from special zoomorphic pots. Next morning, the girls were painted, stupefied with drink, then each laid on a bench were an older woman cut off and buried the clitoris and labia. Reich (1903) adds that the girl was deflowered with a clay penis representing her fiancé. The girls was then isolated in her hut for one month, wearing and eggshaped piece of pottery as a pubic cover". 


\section{REFERÊNCIAS}

Acuña, C. de. 1641. Nuevo Descubrimiento del gran rio de las Amazonas. Madrid: Imprenta del Reino.

Alves, D. T. 2009. Assentos para chefes e pajés: um estudo sobre os bancos de cerâmica marajoara. Relatório de Iniciacão Científica Proc. CNPq no. 502204/2007-9. Belém: Universidade Federal do Pará - UFPA.

Cabalzar, A. 2003. Kumurõ. Banco Tukano. São Paulo: Instituto Socioambiental.

Carvalho, S. M. S. de. 1975. O duplo jacaré (a cerâmica Marajoara). Perspectivas 1:13-34.

Guapindaia, V. 2001. Encountering the ancestors. The Maracá urns. In Unknown Amazon. Culture in nature in ancient Brazil. Editado por C. McEwan, C. Barreto e E. Neves. Londres: The British Museum Press.

Hilbert, P. P. 1952. Contribuição à arqueologia da Ilha de Marajó. Os tesos Marajoaras do alto Camutins e a atual situação da Ilha do Pacoval, no Arari. Instituto de Antropologia e Etnologia do Pará 5:5-32.

McEwan, C. 2001. Seats of Power. Axiality and Access to Invisible Worlds. In Unknown Amazon. Nature and Culture in Ancient Brazil. Editado por C. McEwan, C. Barreto e E. Neves.. Pp. 176-95. London: British Museum Press.

Meggers, B. J. e C. Evans. 1957. Archeological investigations at the mouth of the Amazon. Volume Bulletin 167. Washington, D.C., Smithsonian Institution Bureau of American Ethnology U.S. Govt. Print. Off.

Métraux, A. 1948. Tribes of the Montana and Bolivian East Andes. In Handbook of South American Indians. The tropical forest tribes. Editado por J. Steward. Washington D.C.: Smithsonian Institution. Bureau of American Ethnology.

Nimuendaju, C. 2004. In Pursuit of a Past Amazon. Archaeological researches in the Brazil- ian Guyana and in the Amazon region. Gotenborg: Elanders Infologistik.

Ostapkowicz, J. M. 1998. To be Seated with "Great Courtesy and Veneration": Contextual Aspects of the Taíno Duho. In Taino. Pre-Columbian Art and Culture from the Caribbean. Editado por F. Bercht, E. Brodsky, J.A. Farmer e D. Taylor. Pp. 42-67. New York: El Museo del Barrio/ The Monacelli Press.

Palmatary, H. C. 1950. The pottery of Marajo Island, Brazil. Transactions of the American Philosophical Society 39 (3).

Paschoalick, L. C. A. 2001. A arte dos indios kaiowá da reserva indígena de DouradosMS: transformações e permanências, uma expressão de identidade e afirmação étnica. Dissertação de Mestrado. Dourados: UFMS.

Penna, D. S. F. 1877. Urnas de Maracá. Archivos do Museu Nacional 2:69-71.

Pineda, R. 1994. Los Bancos Taumaturgos. Buletín del Museo del Oro 36:3-39.

Reichel-Dolmatoff, G. 1976. O contexto cultural de um alucinógeno aborígene: Banisteriopsis caapi. In $O s$ alucinógenos e o mundo simbólico. Editado por V.P. Coelho. Pp. 59104. São Paulo: Edusp.

Ribeiro, B. G. 1987. A Linguagem Simbólica da Cultural Material. Introdução. In Suma Etnológica Brasileira Vol. 3. Editado por B. Ribeiro. Petrópolis: Vozes/ FINEP. 1988. Dicionário do artesanato indígena. Belo Horizonte: Itatiaia.

1992. Mitologia: Verdades Fundamentais e Expressão Gráfica. A Mitologia Pictórica dos Desâna. In Grafismo Indígena: Estudos de Antropologia Estética. Editado por L. Vidal. São Paulo: Studio Nobel/ Fapesp/ Edusp.

Roosevelt, A. C. 1991. Moundbuilders of the Amazon: geophysical archaeology on Marajo Island, Brazil. San Diego: Academic Press. 
Schaan, D. P. 1997a. A Linguagem Iconográfica da Cerâmica Marajoara. Um Estudo da Arte Pré-histórica na Ilha de Marajó, Brasil (400-1300AD). Porto Alegre: Edipucrs.

.1997b. Marajoara Iconography: a Structural Approach. Noticias de Antropologia y Arqueologia (Revista Virtual de la Universidad de Buenos Aires, http://www.naya.org.ar/articulos/marajoi. htm) 2(13).

2001a. Estatuetas Marajoara: o simbolismo de identidades de gênero em uma sociedade complexa Amazônica. Boletim do Museu Paraense Emílio Goeldi. Série Antropologia 17(2): 437-477.

2001b. Into the labyrinths of Marajoara pottery: status and cultural identity in an Amazonian complex society. In The Unknown Amazon. Nature in Culture in Ancient Brazil. Editado por C. McEwan, C. Barreto e E.G. Neves. Pp. 108133. London: British Museum Press. 2003. A ceramista, seu pote e sua tanga: identidade e papéis sociais em um cacicado marajoara. Revista de Arqueologia 16:31-45.

.2004. The Camutins Chiefdom: Rise and Development of Complex Societies on Marajó Island, Brazilian Amazon. Tese de Doutorado. Departamento de Antropologia, University of Pittsburgh.

2007. Os Filhos da Serpente: Rito, Mito e Subsistência nos Cacicados da Tha de Marajó. International Journal of South American Archaeology 1:50-56 (http://www.ijsa.syllabapress.com/issues/articles/ijsa00006.pdf).

2009. Cultura Marajoara. Rio de Janeiro: Senac Nacional.

2010. Long-Term Human Induced Impacts on Marajó Island Landscapes, Amazon Estuary. Diversity 2(2):182-206.

Schaan, D. P. eE. T. Rodrigues. no prelo. Landscape management, subsistence economies, and sociocultural change: lessos from eastern Marajo island past, and present. In Amazonias past, present and future - a bio- cultural penspective. Editado por L. Forline e H.P. Silva. Walnut Creek: Left Coast Press.

Urbina, F. 1994. El Hombre Sentado: Mitos, Ritos Y Petroglifos En El Río Caquetá. In Boletim Museo Del Oro 36: 66-111.

Villaça, A. 1993. O Canibalismo Funerário Pakaa-nova: uma Etnografia. In Amazônia: Etnologia e História Indígena. Editado por E.V. de Castro e M.C. da Cunha. São Paulo: NHII/Edusp/Fapesp.

Vincent, W. M. 1987. Máscaras. Objeto ritual do alto rio Negro. In Suma Etnológi ca Brasileira. Vol. 3. Arte Índia. Editado por B.G. Ribeiro. Pp. Petrópolis: Vozes. Zerries, O. 1970. Bancos zoomorfos y asientos de los espíritus en América del Sur. Ateneo Paraguayo. Revista Suplemento de Antropología 5(1-2). 
Apêndice 1

Tipologia da cerâmica da fase marajoara

\begin{tabular}{l|l}
\hline Tipos Cerâmicos & Descrição (parcial) do Tipo \\
(Meggers e Evans 1957:324-370) & $\begin{array}{l}\text { Pasta em Inajá ou Camutins simples. Superfície com } \\
\text { camada espessa de engobo branco (creme ou salmão) } \\
\text { sob o engobo vermelho fino è às vezes polido; linhas } \\
\text { incisas de 1 a 3mm de espessura; motivos diversos. }\end{array}$ \\
\hline Anajás simples inciso & $\begin{array}{l}\text { Pasta em Inajá ou Camutins simples. Motivos deco- } \\
\text { rativos feitos com incisões de 1 ou 2mm de espessu- } \\
\text { ra; as duas espessuras quase nunca são encontradas } \\
\text { na mesma vasilha. O motivo típico é o de grandes } \\
\text { áreas ou bandas contendo linhas retas paralelas. }\end{array}$ \\
\hline Anajás vermelho inciso & $\begin{array}{l}\text { Pasta em Inajá ou Camutins simples. Engobo ver- } \\
\text { melho cinábrio, às vezes com tom alaranjado, pouco } \\
\text { espesso; incisões profundas e bem feitas, com espes- } \\
\text { sura de 1 a 2mm; linhas são raramente retas. }\end{array}$ \\
\hline Anajás branco inciso & $\begin{array}{l}\text { Pasta em sua maioria em Inajá simples, restante em } \\
\text { Camutins simples. Engobo branco (creme ou laranja } \\
\text { claro), frequentemente polido, linhas incisas muito } \\
\text { finas (1mm ou menos) e bem feitas, regulares e às } \\
\text { vezes revelando a pasta laranja. O motivo mais co- } \\
\text { mum é a espiral. }\end{array}$ \\
\hline Arari simples exciso & $\begin{array}{l}\text { Pasta predominante em Inajá simples, às vezes em } \\
\text { Camutins simples. Superfície com camada espessa } \\
\text { de engobo branco (creme, salmão ou marrom claro) } \\
\text { sob o engobo vermelho cinábrio variando a marrom } \\
\text { ou quase preto; combinação de linhas incisas, excisas } \\
\text { e áreas; excisão cobre 40-60\% da superfície. }\end{array}$ \\
\hline Arari com engobo duplo exciso \\
$\begin{array}{l}\text { Pasta em Inajá ou Camutins simples. Combinação } \\
\text { de linhas finas incisas com áreas excisas, variando } \\
\text { desde poucas linhas excisas com até 75\% da superfí- } \\
\text { cie removida com excisão. }\end{array}$ \\
$\begin{array}{l}\text { Pasta em Inajá ou Camutins simples. Engobo ver- } \\
\text { melho escuro, puxando para o marrom ou preto } \\
\text { ocasionalmente; incisões em linhas finas ou grossas } \\
\text { combinadas com excisões em várias proporções. O } \\
\text { motivo mais comum é o escalonado, sozinho ou } \\
\text { combinado com linhas sinuosas e outras figuras. }\end{array}$ \\
\hline
\end{tabular}




\begin{tabular}{|c|c|}
\hline $\begin{array}{l}\text { Arari vermelho exciso com re- } \\
\text { toque branco }\end{array}$ & $\begin{array}{l}\text { Pasta em sua maioria em Inajá simples, restante em } \\
\text { Camutins simples. Engobo vermelho cinábrio a } \\
\text { vermelho escuro de textura fina, às vezes polido; in- } \\
\text { cisões e excisões combinadas em proporções iguais, } \\
\text { com excisões com profundidade de } 1 \mathrm{~mm} \text {, cobertas } \\
\text { com pintura vermelha espessa. }\end{array}$ \\
\hline Arari branco exciso & $\begin{array}{l}\text { Pasta predominante em Inajá simples, às vezes em } \\
\text { Camutins simples. Engobo branco (ou creme a } \\
\text { salmão), combinação de excisões e incisões; excisão } \\
\text { é tipicamente pouco profunda, mas às vezes penetra } \\
\text { na pasta revelando sua cor alaranjada. }\end{array}$ \\
\hline Camutins simples & $\begin{array}{l}\text { Manufaturado com roletes de } 2 \text { a } 3 \mathrm{~mm} \text {, tempero de } \\
\text { caco moído, com partículas chegando a } 5 \mathrm{~mm} \text {, textura } \\
\text { porosa, tempero pouco misturado, queima oxidante. }\end{array}$ \\
\hline Carmelo vermelho & $\begin{array}{l}\text { Pasta em Inajá ou Camutins simples. Engobo vermelho } \\
\text { cinábrio a vermelho escuro, ocasionalmente vermelho } \\
\text { alaranjado; espessura fina, às vezes apenas um banho. }\end{array}$ \\
\hline Goaipi raspado & $\begin{array}{l}\text { Pasta em Inajá ou Camutins simples. Estrias produ- } \\
\text { zidas com grande variedade de instrumentos, com } \\
\text { resultados heterogêneos. }\end{array}$ \\
\hline Guajará inciso & $\begin{array}{l}\text { Pasta tipicamente em Camutins simples, às vezes em } \\
\text { Inajá simples. Motivos decorativos executados com } \\
\text { instrumento de duas pontas, produzindo duas linhas } \\
\text { paralelas uniformes; raramente ocorrem três linhas. }\end{array}$ \\
\hline Inajá simples & $\begin{array}{l}\text { Manufaturado com roletes de } 2 \text { a } 5 \mathrm{~mm} \text {, tempero } \\
\text { de caco moído, com partículas chegando a } 5 \mathrm{~mm} \text {, } \\
\text { textura porosa, tempero pouco misturado, queima } \\
\text { incompleta. }\end{array}$ \\
\hline Joanes pintado & $\begin{array}{l}\text { Pasta em Inajá ou Camutins simples. Pintura vermelha } \\
\text { e/ou preta sobre engobo branco, em linhas ou com- } \\
\text { binação de linhas com áreas sólidas. Ocorre associa- } \\
\text { do com diversas outras técnicas de incisão e excisão. }\end{array}$ \\
\hline Pacoval inciso & $\begin{array}{l}\text { Pasta predominantemente em Inajá simples, ocasional- } \\
\text { mente em Camutins simples. Engobo branco (às vezes } \\
\text { creme ou alaranjado), de textura fina, linhas incisas finas e } \\
\text { largas (1-3mm) estas últimas geralmente pintadas ou "re- } \\
\text { tocadas" com pintura vermelha. Ocorrem também áreas } \\
\text { limitadas por incisões e pintadas de vermelho. }\end{array}$ \\
\hline
\end{tabular}




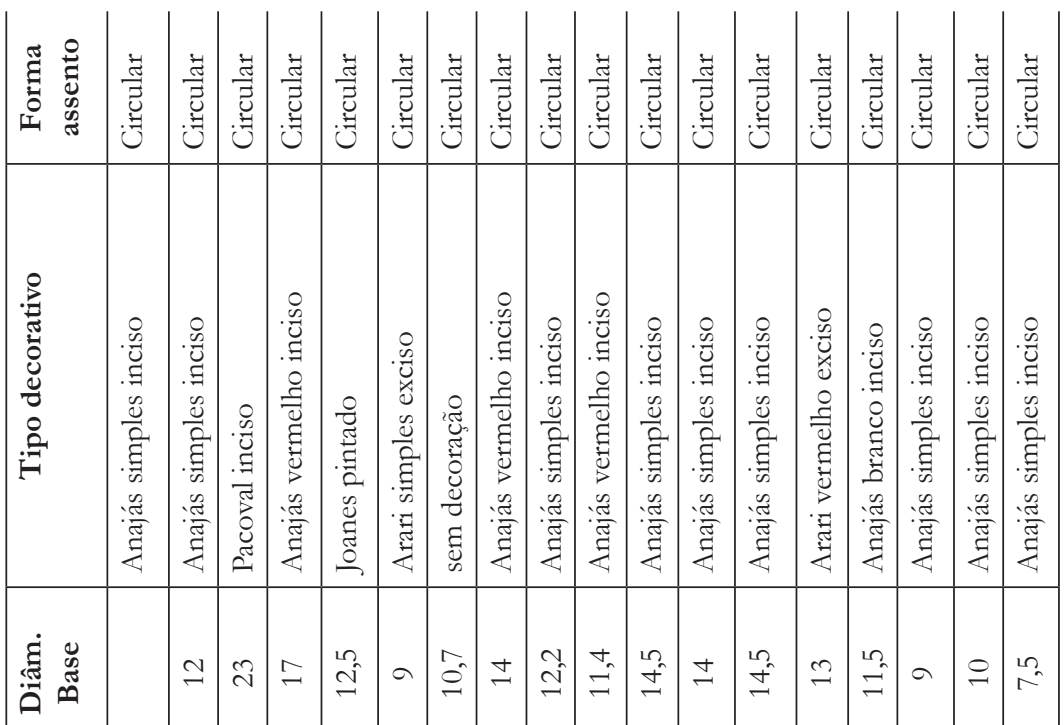

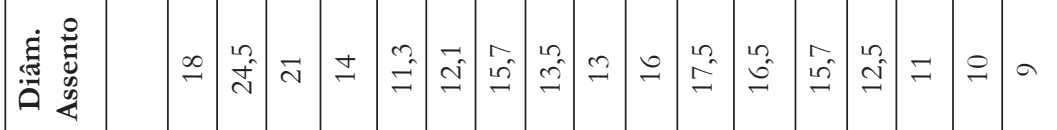

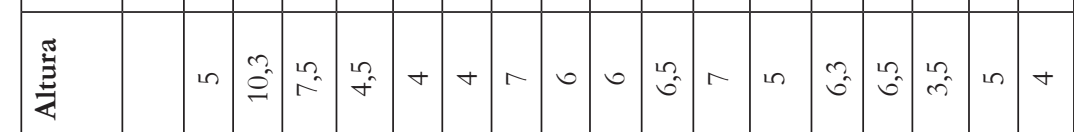

\begin{tabular}{|c|c|c|c|c|c|c|c|c|c|c|c|c|c|c|c|c|c|c|}
\hline 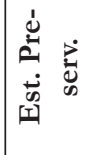 & & . & $\begin{array}{l}\text {. } \\
\text {. } \\
\text {. }\end{array}$ & 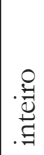 & 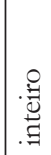 & \begin{tabular}{|l}
. \\
. \\
.
\end{tabular} & 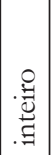 & 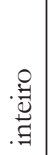 & $\begin{array}{l}0 \\
.09 \\
.9\end{array}$ & 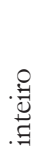 & 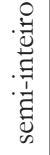 & 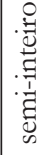 & 章 & & & & & 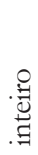 \\
\hline
\end{tabular}

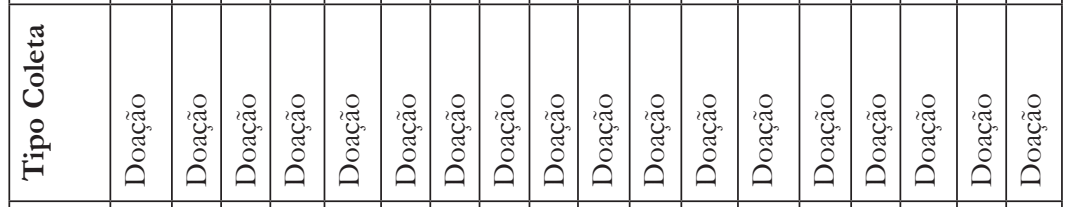

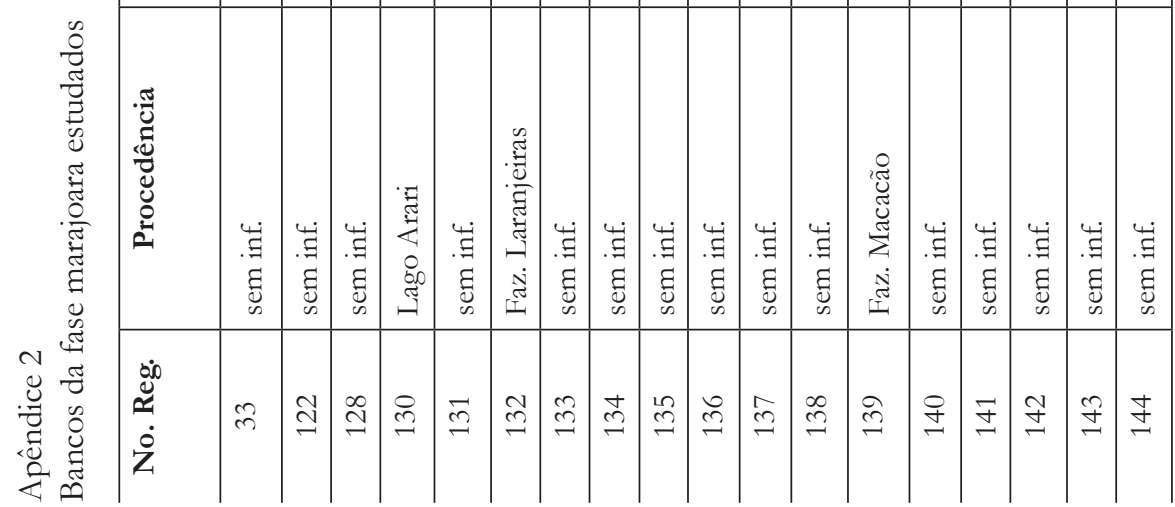




\begin{tabular}{|c|c|c|c|c|c|c|c|c|c|c|c|c|c|c|c|c|c|c|c|c|}
\hline 氙 & & 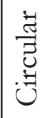 & 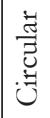 & 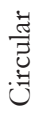 & 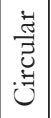 & 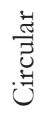 & 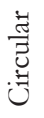 & 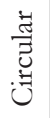 & 䓂 & 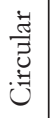 & 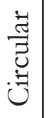 & 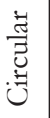 & 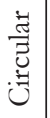 & 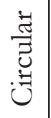 & & 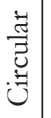 & 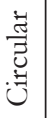 & 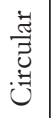 & 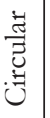 & 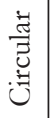 \\
\hline 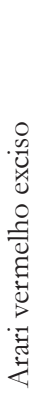 & 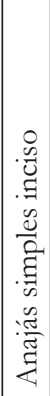 & 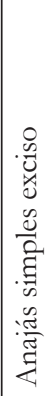 & 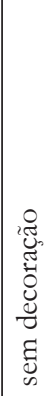 & 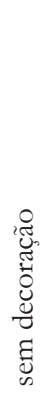 & 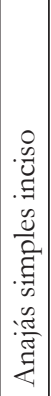 & 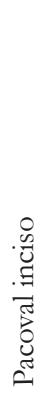 & 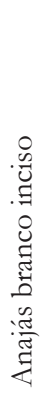 & 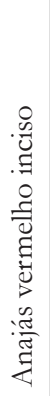 & 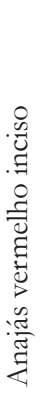 & 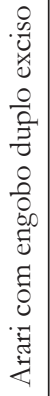 & 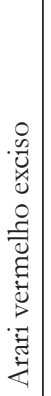 & 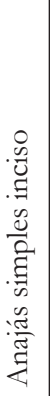 & 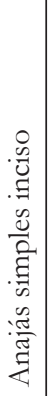 & 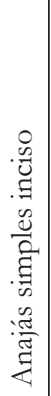 & 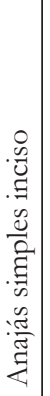 & 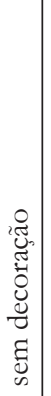 & 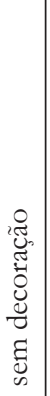 & 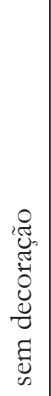 & 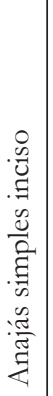 & 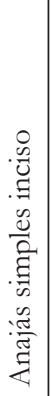 \\
\hline & & 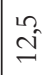 & & & & & & $\cong$ & $\stackrel{ }{\circ}$ & 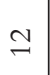 & $\stackrel{0}{\sim}$ & & & $\overbrace{0}^{2}$ & 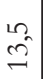 & & & & & \\
\hline 4 & $\stackrel{2}{\sim}$ & $\stackrel{2}{2}$ & \pm & $\exists$ & 0 & $\stackrel{\sim}{\sim}$ & $\stackrel{\sim}{\sim}$ & $\stackrel{n}{=}$ & $\stackrel{\sim}{二}$ & $\stackrel{n}{=}$ & $\begin{array}{l}n \\
0 \\
\sim \\
-\end{array}$ & $\begin{array}{l}\hat{\star A} \\
\stackrel{A}{n}\end{array}$ & $\stackrel{2}{7}$ & $\stackrel{0}{\circ}$ & \pm & $\tilde{\vartheta}^{\sim}$ & 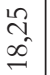 & $\begin{array}{l}n \\
\stackrel{n}{n} \\
\sim\end{array}$ & $\stackrel{\infty}{\longrightarrow}$ & $\neg$ \\
\hline
\end{tabular}

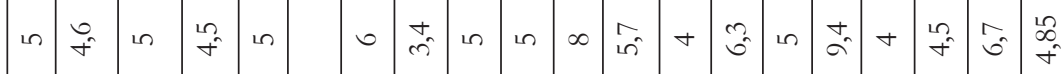

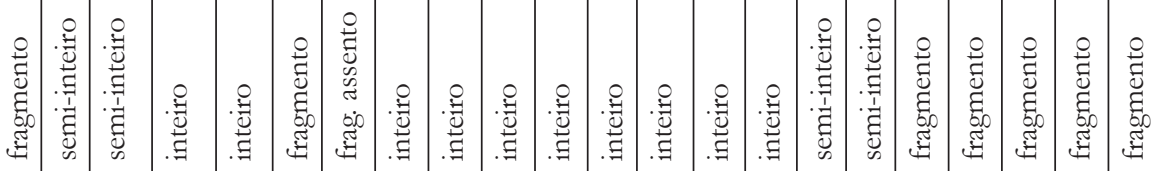

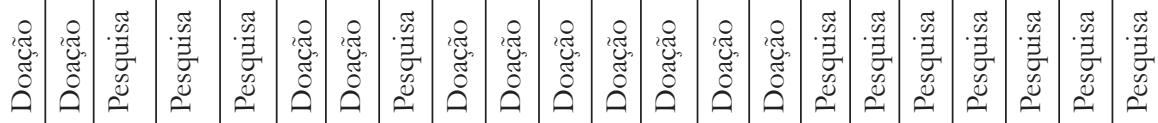

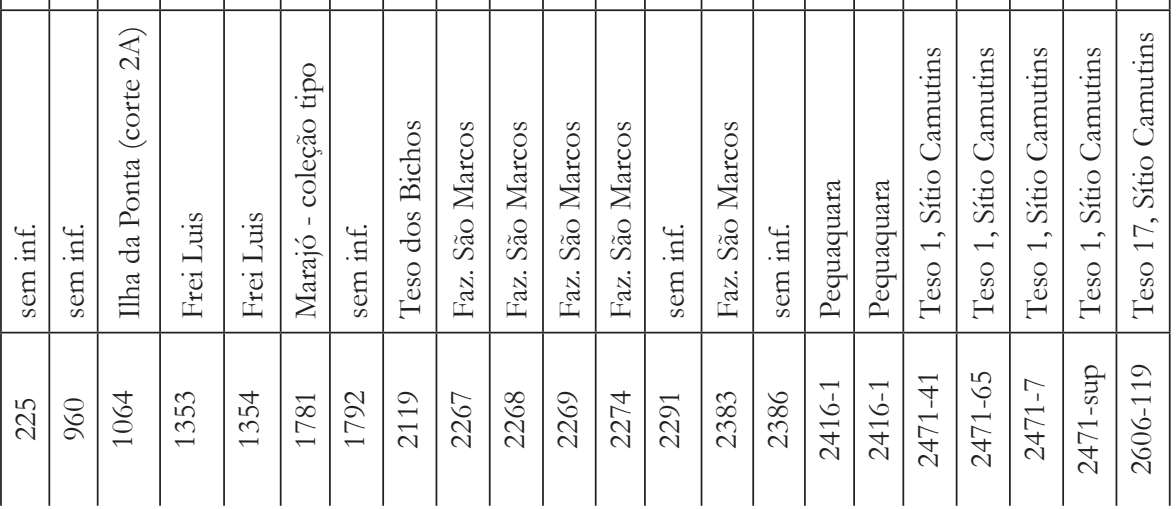




\begin{tabular}{|c|c|c|c|c|c|c|c|c|c|c|c|c|c|c|c|c|c|c|c|c|c|}
\hline 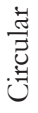 & 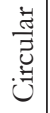 & 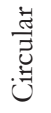 & 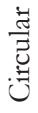 & $\begin{array}{l}\text { 莺 } \\
\text { 总 }\end{array}$ & 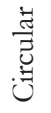 & 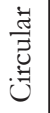 & 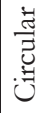 & 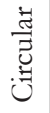 & 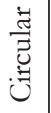 & 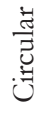 & $\begin{array}{l}\text { 莺 } \\
\text { 总 }\end{array}$ & 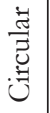 & 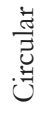 & 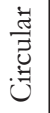 & $\begin{array}{l}\frac{\vec{J}}{\vec{J}} \\
\stackrel{⿹}{U}\end{array}$ & 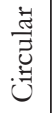 & 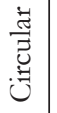 & 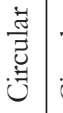 & 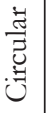 & 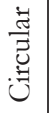 & 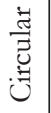 \\
\hline 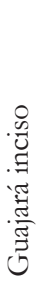 & 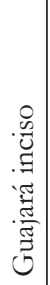 & 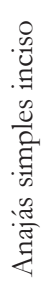 & 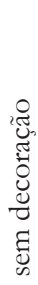 & 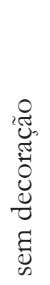 & 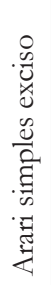 & 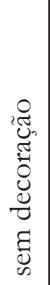 & 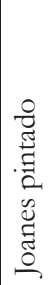 & 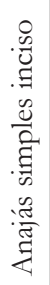 & 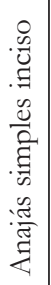 & 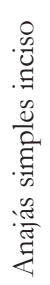 & 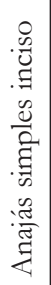 & 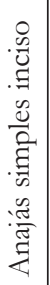 & 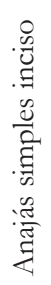 & 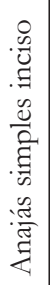 & 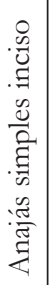 & 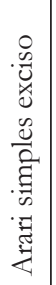 & 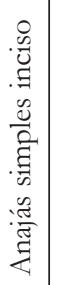 & 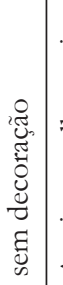 & 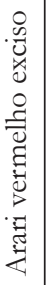 & 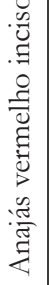 & 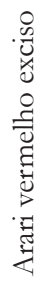 \\
\hline & & & 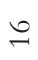 & & & & & & & & & $\cong$ & & & $\begin{array}{l}\stackrel{n}{c} \\
\mathfrak{c}\end{array}$ & & & $\begin{array}{l}\hat{n} \\
\stackrel{f}{f}\end{array}$ & & & \\
\hline$\stackrel{n}{\sim}$ & $\vec{\sim}$ & $\stackrel{\sim}{ }$ & $\stackrel{\nu}{ }$ & $\stackrel{\sim}{ }$ & $\widetilde{N}$ & $\vec{\sim}$ & & & \pm & $\stackrel{0}{\sim}$ & \pm & $\stackrel{0}{\sim}$ & $\stackrel{\sim}{\sim}$ & \pm & $\exists$ & $\stackrel{m}{\rightarrow}$ & 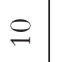 & $\exists$ & $\stackrel{n}{\alpha}$ & $\approx$ & $\begin{array}{l}\infty \\
\infty \\
\infty\end{array}$ \\
\hline & & $\stackrel{m}{n}$ & $r$ & & & & & & & & & $\begin{array}{l}i^{n} \\
n^{\circ}\end{array}$ & & & 0 & $m$ & $\exists$ & ○ & & & \\
\hline 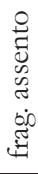 & 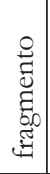 & 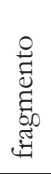 & 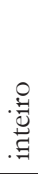 & 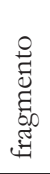 & 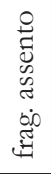 & 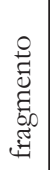 & 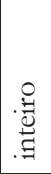 & 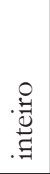 & 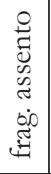 & 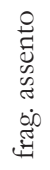 & 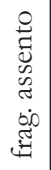 & 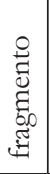 & 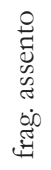 & 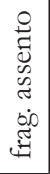 & 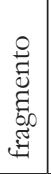 & 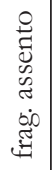 & 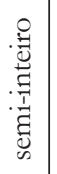 & 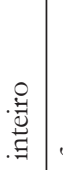 & 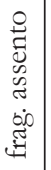 & 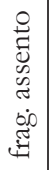 & 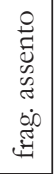 \\
\hline
\end{tabular}

\begin{tabular}{|c|c|c|c|c|c|c|c|c|c|c|c|c|c|c|c|c|c|c|c|c|c|}
\hline 气 & 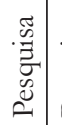 & 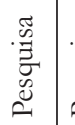 & 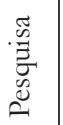 & 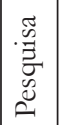 & 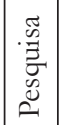 & 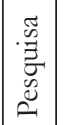 & 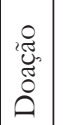 & 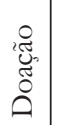 & 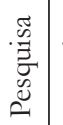 & 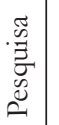 & 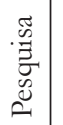 & 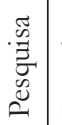 & 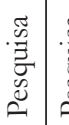 & & 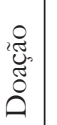 & 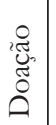 & 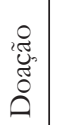 & 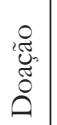 & 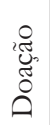 & 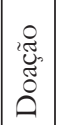 & 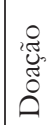 \\
\hline$E$ & 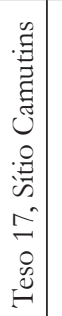 & 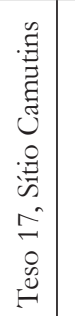 & 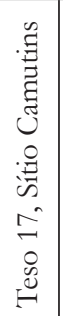 & 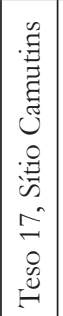 & 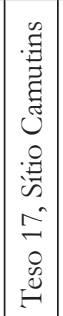 & 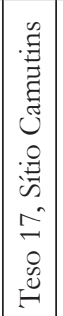 & 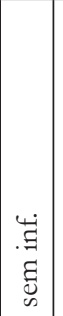 & 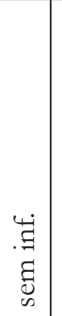 & 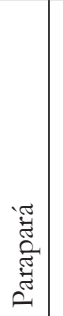 & 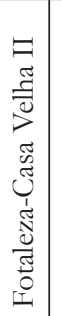 & 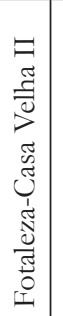 & 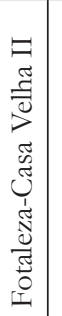 & 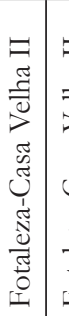 & 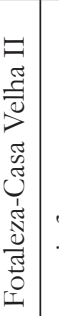 & 荘 & 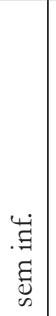 & 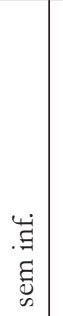 & 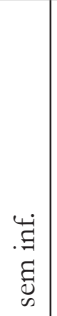 & 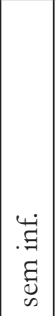 & 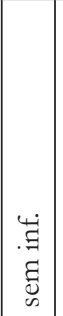 & $\begin{array}{l}\text { 㟧 } \\
\text { घ्ञ }\end{array}$ \\
\hline & 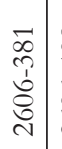 & 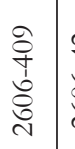 & 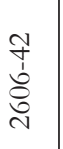 & $\begin{array}{l}n \\
\hat{1} \\
\delta \\
0 \\
0 \\
\text { N. }\end{array}$ & $\begin{array}{l}n \\
n \\
1 \\
\delta \\
0 \\
0 \\
d \\
\end{array}$ & 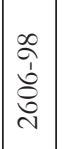 & 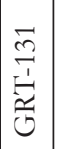 & 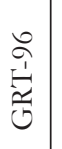 & $\stackrel{\substack{\tilde{n} \\
0}}{0}$ & $\begin{array}{l}\overrightarrow{0} \\
\substack{1 \\
\hat{n} \\
0}\end{array}$ & 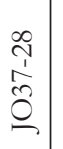 & 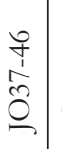 & 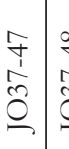 & 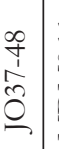 & 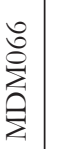 & 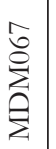 & 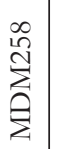 & 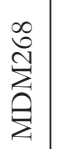 & 蒿 & $\stackrel{\stackrel{n}{\hat{\jmath}}}{\stackrel{\grave{\Xi}}{\mathrm{g}}}$ & 离 \\
\hline
\end{tabular}




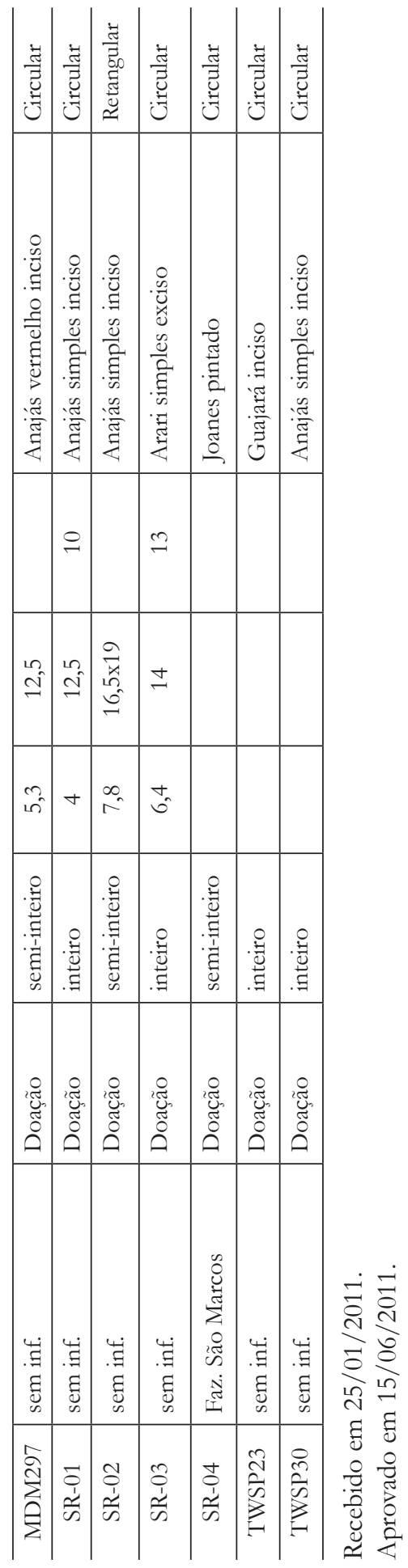

